\title{
Magnetized Chitosan Nanocomposite as an Effective Adsorbent for the Removal of Methylene Blue and Malachite Green Dyes
}

\section{Fouzia Mashkoor}

Aligarh Muslim University Faculty of Engineering and Technology

Abu Nasar ( $\square$ abunasaramu@gmail.com )

Aligarh Muslim University https://orcid.org/0000-0001-8796-3077

\section{Research Article}

Keywords: Adsorption, Dye, Malachite green, Methylene blue, Wastewater treatment, Magnetized chitosan

Posted Date: March 9th, 2021

DOI: https://doi.org/10.21203/rs.3.rs-233253/v1

License: (c) (i) This work is licensed under a Creative Commons Attribution 4.0 International License.

Read Full License

Version of Record: A version of this preprint was published at Biomass Conversion and Biorefinery on January 4th, 2022. See the published version at https://doi.org/10.1007/s13399-021-02282-3. 
1 Magnetized chitosan nanocomposite as an effective adsorbent for the removal of methylene

2 blue and malachite green dyes

3 Fouzia Mashkoor, Abu Nasar*

4 Department of Applied Chemistry, Faculty of Engineering and Technology, Aligarh Muslim 5 University, Aligarh - 202 002, India

\section{Abstract}

8 Herein, a magnetically separable $\mathrm{Fe}_{3} \mathrm{O}_{4}$ decorated chitosan was facilely synthesized, 9 systematically characterized, and subsequently employed as a versatile adsorbing material for the 10 adsorption of malachite green and methylene blue dyes. The prepared adsorbent was 11 characteristically examined through Fourier transform infra-red microscopy, scanning electron 12 microscopy with energy-dispersive X-ray analysis, transmission electron microscopy X-ray 13 diffraction, Brunauere-Emmette-Teller surface area analysis, thermogravimetric analysis, and 14 vibrating-sample magnetometry techniques. The performance of adsorbent was studied in batch 15 mode and the the time-dependent experimental data were analyzed with different kinetic models, 16 and pseudo-II ${ }^{\text {nd }}$-order was provided the best fit for the adsorption of both the dyes with a high

17 value of the regression coefficient. The adsorption equilibrium data of both the dyes was best 18 explained by Langmuir isotherm, and the maximum sorption capacity of MG and MB was found 19 to be 55.86 and $76.34 \mathrm{mg} \mathrm{g}^{-1}$, respectively. Thermodynamic analysis declared that the adsorption 20 of MG and MB onto the MChi was endothermic and spontaneous in nature. Moreover, the 21 adsorbent presented good reusability up to three successive ad-/de-sorption cycles, indicating 22 that MChi is a promising applicant for the treatment of dye-containing wastewater. 
24 *Corresponding author. E-mail address: abunasar@zhcet.ac.in, abunasaramu@ gmail.com (A.

25 Nasar)

26

27 Keywords: Adsorption; Dye; Malachite green; Methylene blue; Wastewater treatment;

28 Magnetized chitosan

\section{Introduction}

31 Water lack is one of the most severe worries that our world is confronting nowadays (Franco et 32 al. 2019). By 2050 , over $40 \%$ of the world population is expected to live in regions of extreme 33 water scarcity (Novais et al. 2018). The inexorable decline in the quality and availability of 34 drinking water is undoubtedly the consequence of the increasing growth of the world population 35 and unsustainable industrial development. Water is polluted by the inevitable discharge of 36 industrial wastewater comprising numerously non-biodegradable and hazardous inorganic and 37 organic contaminants like heavy metals, pesticides, dyes, cosmetics, and pharmaceuticals, etc. 38 (Lehman et al. 2011; Kant 2012; Zhao et al. 2013, 2015; Tomar et al. 2014; Qamruzzaman and 39 Nasar 2015, 2019; Ippolito and Fait 2019; Quesada et al. 2019; Jain et al. 2019, 2020; Agarwal et 40 al. 2020). Among these contaminants, the discharge of dyeing sewage from various industries 41 have triggered visual severe water pollution and reduces the water transparency due to extremely 42 high color strength, and leading to a corresponding rise in the concentration of organic matter in 43 water bodies. In addition, it restrains the photosynthesis activity and ends up interfering with 
44 aquatic biological processes and imparting enduring potential harm to the ecosphere and humans 45 as well (Jafari et al. 2015; Shakoor and Nasar 2016; Nasar and Mashkoor 2019; Kang et al. 46 2020). Hence, from the viewpoint of environmental safeguard, it is an extremely imperative 47 prerequisite to developing high performance and eco-friendly technology to eliminate or 48 minimize the content of dyes present in industrial sewage before releasing into the receiving 49 water system. Nowadays, the techniques for the treatment of dyes-laden effluent include 50 photocatalytic degradation, electrochemical treatment, biological method, membrane separation, 51 adsorption, and so on.

Nevertheless, while these methods described above have many constrictions, compared to 53 them, adsorption has demonstrated to be more efficient as it offers many advantages such as 54 simplicity in design, cost-effective, eco-friendly, and easy to operate (Hokkanen et al. 2016; 55 Shakoor and Nasar 2017; Mashkoor and Nasar 2020a; Mashkoor et al. 2020). Primarily, the 56 contaminant elimination act of the adsorption technique is mainly dependent on the 57 characteristics of the adsorbing material like high porosity and surface area, remarkable 58 adsorption capacity, a large number of exposed functional groups and chemical resistance, etc. 59 Thus, recent studies have shown that many researcher have made outstanding efforts to produce 60 several efficient adsorbents that have been utilized magnificently for the removal of toxic 61 pollutants from wastewater.

Natural polymer and its derivatives have possessed remarkable benefits of low cost and 63 abundance and the presence of numerous functional groups in the wastewater application (Lou et 64 al. 2019). For instance, chitosan (Chi) has already been well-known as the most plentiful 65 naturally occurring biopolymers. Chi has captivating characteristics, such as nonhazardous, 66 hydrophilicity, antibacterial property, biodegradability, and biocompatibility (Vakili et al. 2019; 
67 Sabar et al. 2020). The presence of hydroxyl and amino groups in its molecular chain has served

68 as favorable binding sites for both cationic and anionic contaminants present in the wastewater

69 (Lou et al. 2019). However, owing to the high solubility of Chi at $\mathrm{pH}$ less than 5.5, it is

70 challenging to be separated and recovered by traditional separation techniques, such as high-

71 speed centrifugation and filtration (Fan et al. 2012). Tailoring of Chi with magnetic particles is

72 an efficient way to overcome these limitations since magnetized chitosan possesses the benefits

73 of both chitosan (admirable adsorption efficiency) and magnetic material (easy magnetic

74 separability) (Chen et al. 2019).

Here in this report, a stable and magnetically recyclable Chi based bioadsorbent was 76 prepared and explored for the adsorption of two different pollutant dyes, i.e., cationic malachite

77 green $(\mathrm{MG})$, and methylene blue (MB). The adsorption performance of MChi to eliminate the

78 abovementioned dyes were systematically examined at various adsorbate concentrations, MChi

79 dosage, $\mathrm{pH}$ of the solution, adsorbate/adsorbent interaction time, and temperature. The rigorous

80 analyses of adsorption data were carried out in the light of popular kinetic and isotherm models.

81 Moreover, the regeneration experiments of exhausted MChi were executed with the inexpensive 82 desorbing materials, which also demonstrated its promising utility in the wastewater 83 management.

\section{Materials and methods}

\section{Materials}

86 Microscopic grade of dyes (MB and MG) other chemicals (anhydrous ferric chloride, ferrous

87 chloride dihydrated, potassium nitrate, glacial acetic acid, sodium hydroxide, and hydrochloric 88 acid) each of analytical reagent grade procured from Central Drug House, India were used. The 
89 extra pure chitosan of medium molecular weight obtained from Sisco Research Laboratories,

90 India were used as received.

\section{$91 \quad$ Preparation of $\mathrm{MChi}$}

92 The MChi was prepared by incorporating $\mathrm{Fe}_{3} \mathrm{O}_{4}$ particles to Chi by adopting a method similar to 93 our previous work details of was described earlier (Mashkoor and Nasar 2020b).

\section{Characterizations}

96 All Characterization and analysis methods are provided in supporting information (Text S1).

\section{Adsorption procedure}

98 The MG and MB adsorption onto the MChi was appraised using batch methods. The dye

99 solution of the desired concentration was obtained by appropriate dilution of a stock solution ( $1 \mathrm{~g}$

$100 \mathrm{~L}^{-1}$ ). Specifically, MChi adsorbent was transferred into the $30 \mathrm{ml}$ of dye solution, the $\mathrm{pH}$ of 101 which was adjusted with $0.1 \mathrm{M} \mathrm{NaOH}$ or $\mathrm{HCl}$ solutions. After the acquirement of equilibrium, 102 the adsorbate-loaded magsorbent was separated from the solution employing an external 103 magnetic field, and the left over-concentration of dye was analyzed by UV-VIS 104 spectrophotometer (Thermo Scientific, Evolution 201) at $\lambda_{\max }$ of $617 \mathrm{~nm}$ for MG and $665 \mathrm{~nm}$ for 105 MB.

The adsorption capacity (q) at any moment (t)/equilibrium (e) of MChi and the removal 107 efficiency (RE \%) were calculated according to equations 1 and 2, respectively (Mashkoor et al. 108 2018): 


$$
\mathrm{q}_{\mathrm{t} / \mathrm{e}}=\frac{\mathrm{v}}{\mathrm{m}} \times\left(\mathrm{C}_{\mathrm{o}}-\mathrm{C}_{\mathrm{t} / \mathrm{e}}\right)
$$

$$
\mathrm{RE} \%=\frac{\left(\mathrm{C}_{0}-\mathrm{C}_{\mathrm{t} / \mathrm{e}}\right)}{\mathrm{C}_{0}} \times 100
$$

111 where $\mathrm{C}_{\mathrm{o}}$ and $\mathrm{C}$ are the initial and residual dye concentration at any moment/equilibrium (t/e) in

$112 \mathrm{mg} \mathrm{L}^{-1}$, respectively. $\mathrm{V}$ is the volume of adsorbate solution $(\mathrm{L}), \mathrm{m}$ is the MChi dosage $(\mathrm{g})$.

113 For the acquisition of the optimal value, the influence of MChi dose $\left(0.4-6 \mathrm{~g} \mathrm{~L}^{-1}\right), \mathrm{pH}$ of the dye

114 solution (4-11), contact time (2-240 min), and initial adsorbate concentration (15-100 $\left.\mathrm{mg} \mathrm{L}^{-1}\right)$

115 was studied by batch technique. The influence of temperature $(303-333 \mathrm{~K})$ was also 116 investigated.

\section{Desorption and regeneration study of the MChi}

119 The possibility of recycling the MChi was evaluated using $0.1 \mathrm{M} \mathrm{HCl}$ and ethanol as a desorbing 120 agent for the desorption of MG and MB from the MChi. The experiments were performed by 121 adding dye saturated adsorbent into the $30 \mathrm{ml}$ of aforementioned desorbing agents at $30{ }^{\circ} \mathrm{C}$ and

122 left for $4 \mathrm{~h}$ for desorption equilibrium. A similar method of ad-/de-sorption cycles was replicated 123 to reappraise the performance of the MChi till the removal of dye become inconsequential. The 124 concentration of dye in the solution after every ad-/de-sorption cycle was determined, and 125 percent desorption (D\%) was evaluated using equation 4:

$126 \quad \mathrm{D} \%=\frac{\mathrm{W}_{\mathrm{des}}}{\mathrm{W}_{\mathrm{ads}}} \times 100$

127 where, $\mathrm{W}_{\text {ads }}$ is the amount dye adsorbed, and $\mathrm{W}_{\text {des }}$ is the amount of dye desorbed in $\mathrm{mg} \mathrm{L}^{-1}$. 


\section{$128 \quad$ Results and discussion}

\section{Adsorbent characterization}

130 The Fourier transform infra-red (FTIR) spectra of MChi illustrated in Fig. 1 was consisted of

131 characteristic peaks at 3407 and $2926 \mathrm{~cm}^{-1}$, attributed to the axial stretching vibrations of O-H

132 and N-H groups (Prasad and Joseph 2017). A small peak near $2857 \mathrm{~cm}^{-1}$ was endorsed to the

133 stretching vibrations of $\mathrm{C}-\mathrm{H}$, and the band of significant intensity around $1637 \mathrm{~cm}^{-1}$ was due to

134 the stretching vibrations of amide I ( $\mathrm{NH}$ deformation of $\left.-\mathrm{NHCOCH}_{3}\right)$. Peaks appeared at 1460

135 and $1382 \mathrm{~cm}^{-1}$ were attributed to coupling of C-N axial stretching and N-H angular deformation,

136 respectively. The peak at $1068 \mathrm{~cm}^{-1}$ was allocated to the $\mathrm{C}-\mathrm{O}-\mathrm{C}$ stretching vibration, and one

137 additional peak at $562 \mathrm{~cm}^{-1}$ was due to the stretching vibration of Fe-O (Bagheri et al. 2014). 


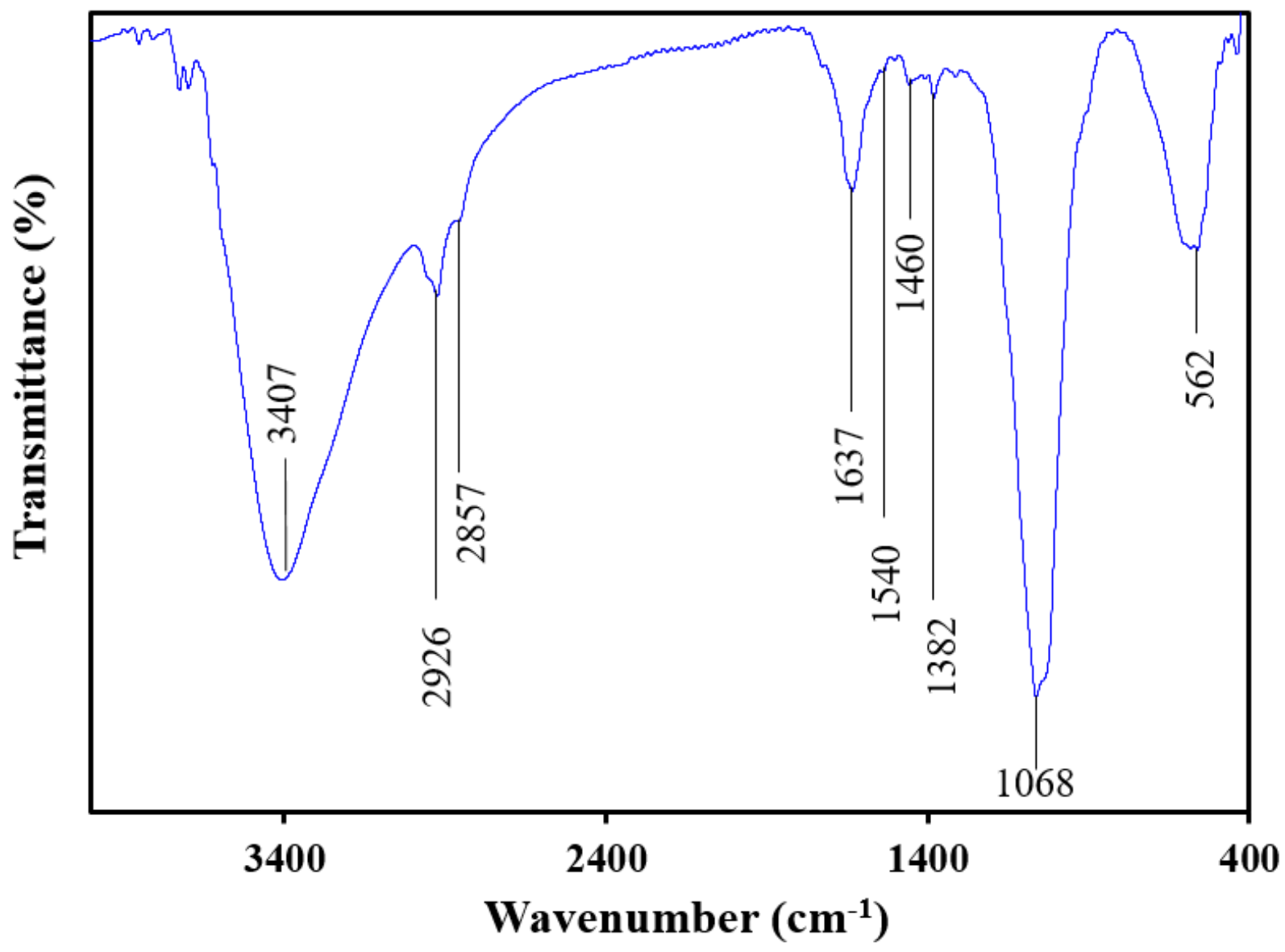

Fig. 1 (a) FTIR of MChi

The morphology of MChi nanocomposite was characterized by transmission electron microscopy (TEM) and scanning electron microscopy (SEM) observations. The TEM images of

144 MChi presented in Fig. 2a revealed the smaller and compact nanoparticles which comprise of 145 dark color ellipsoidal and spherical shaped particles of $\mathrm{Fe}_{3} \mathrm{O}_{4}$ and the light contrast matrix of Chi.

146 The SEM image of MChi (Fig. 2b) indicated the agglomerated light color mass of Chi present on 147 the surface of uniformly distributed particles of $\mathrm{Fe}_{3} \mathrm{O}_{4}$. The energy-dispersive $\mathrm{X}$-ray analysis 148 (EDAX) and elemental mapping of the nanoparticles, as shown in Fig. 2c and Fig. 2d, 149 respectively, ensured the occurrence of $\mathrm{C}, \mathrm{O}$ and Fe elements in the composite of MChi. 

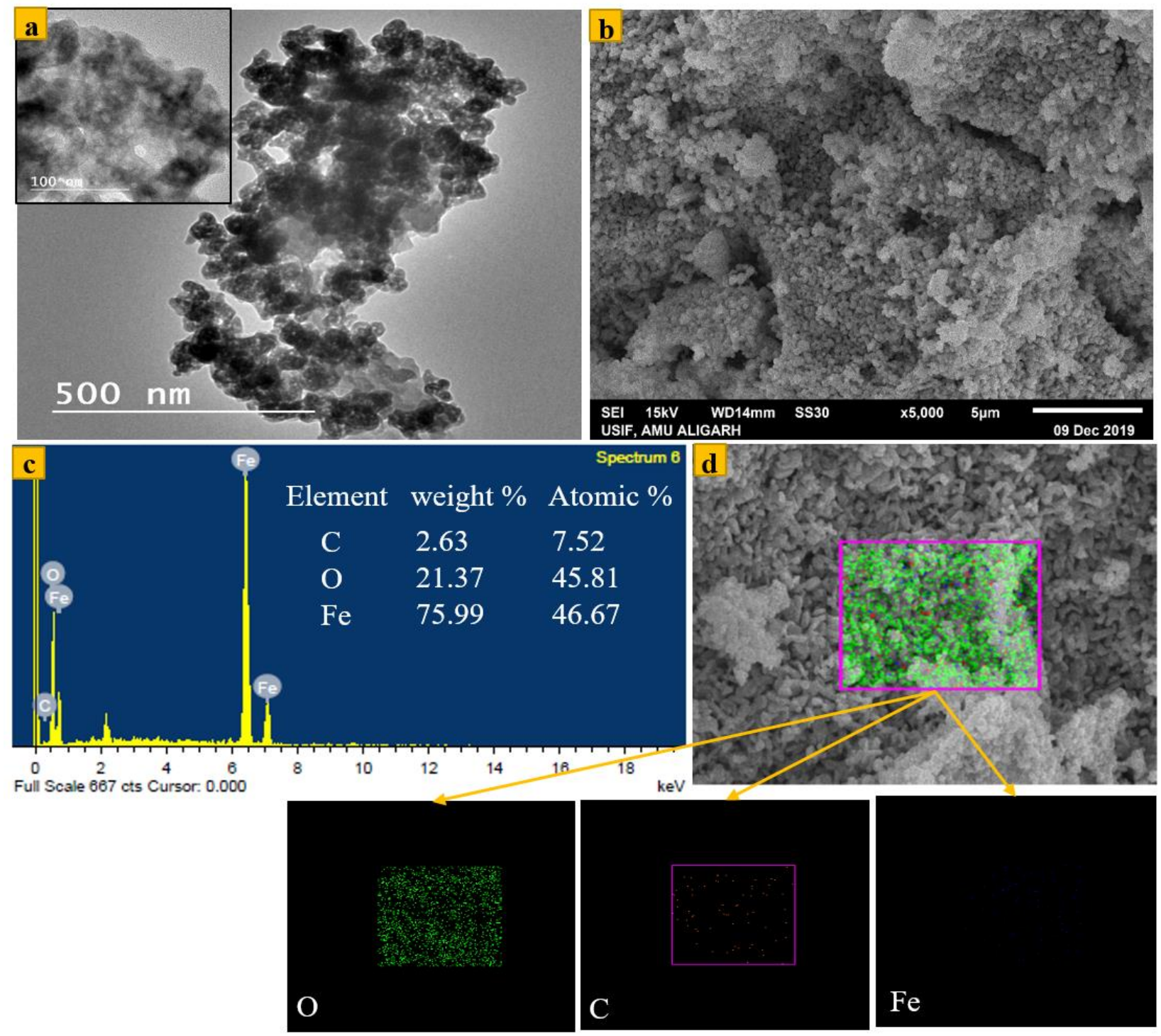

151 Fig. 2 (a) TEM images (b) SEM image (c) EDAX image (d) Elemental mapping of MChi

In order to examine the surface area and porosity of the MChi, $\mathrm{N}_{2}$ ad-/de-sorption

153 isotherms were enumerated (Fig. 3a). The shape of the curve specified in essence is the type-IV

154 isotherm according to IUPAC nomenclature with the mesoporous characteristic of the MChi and

155 is represented in Fig. 3a. Moreover, the interpretation of the hysteresis loop exemplified the

156 existence of type H3 loop, as outlined in the literature (Qi et al. 2017). The obtained results

157 indicated that the Brunauere-Emmette-Teller (BET) surface area of MChi was about $39.99 \mathrm{~m}^{2} \mathrm{~g}^{-}$ 
158 1. According to the Barrett-Joyner-Halenda (BJH) analyses (Fig. 3a'), the MChi possess the 159 average pore width of $39.9751 \mathrm{~nm}$, which also corresponds to the mesoporous nature of the 160 materials.

The magnetic behavior of MChi was studied by vibrating-sample magnetometry (VSM)

162 at room temperature, and the typical magnetic curve and the values of the magnetic properties of 163 MChi are presented in Fig. 3b and b', respectively. The saturation magnetization of MChi was $16428.645 \mathrm{emu} \mathrm{g}^{-1}$, demonstrating the magnetic nature of the composite, which is sufficient enough 165 for conventional magnetic separation. The respective values of intrinsic coercivity and retentivity 166 determined from VSM for MChi were $54.507 \mathrm{Oe}$, and $2.9258 \mathrm{emu} \mathrm{g}^{-1}$. The magnetic hysteresis 167 loop of MChi (Fig. 3b) displayed an S-shaped curve with low value of retentivity, which 168 signifies good dispersibility and easy demagnetization. Therefore, MChi may be a worthy 169 candidate for the wastewater remediation and may be efficiently isolated from water by 170 employing a magnetic field (Saravanakumar et al. 2019). 

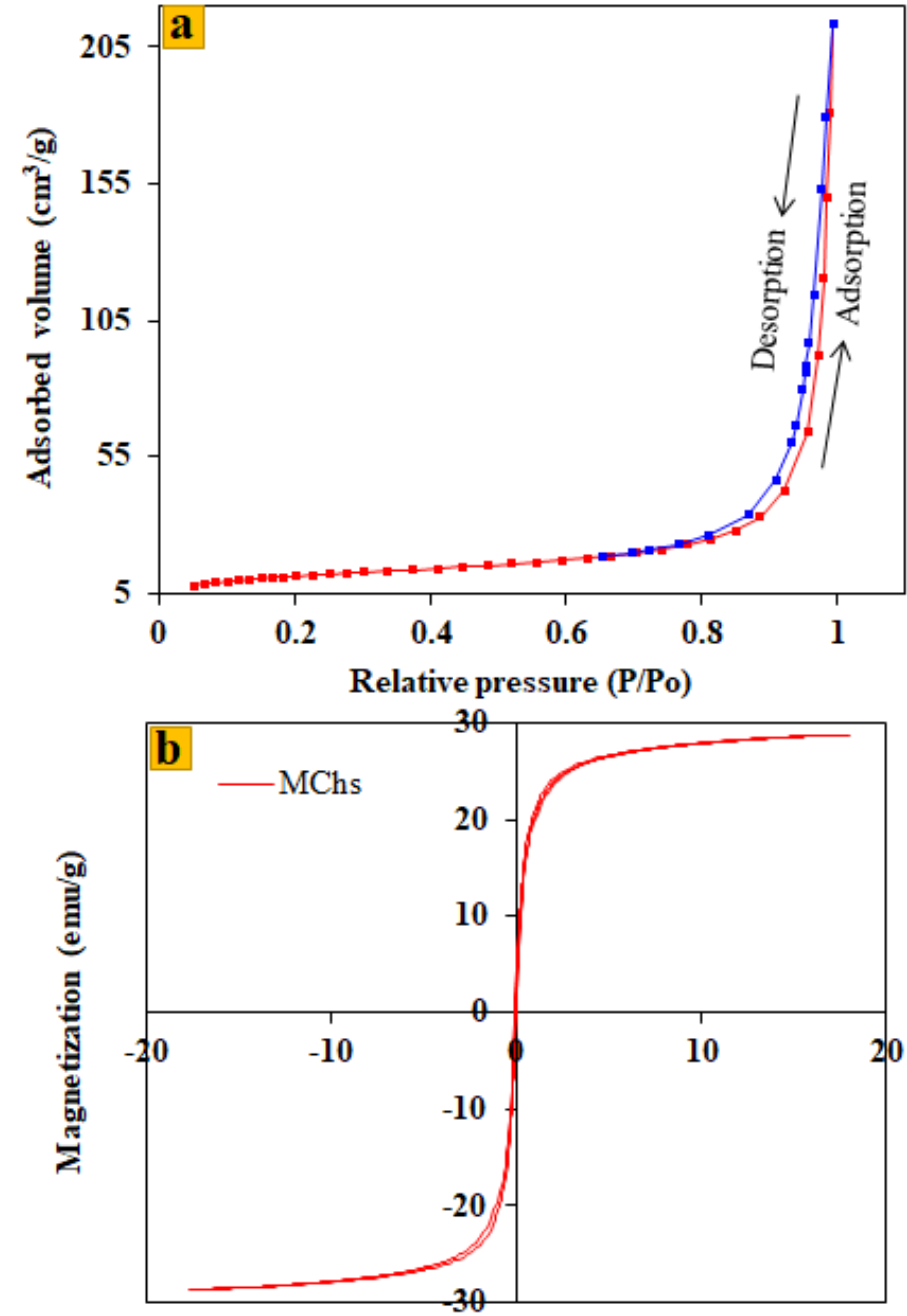

Magnetic field (kOe) (a') Summary of the BET analysis of MChi

Parameters Values

Single-point surface area at $\mathrm{P} / \mathrm{P}_{\mathrm{o}}=0.3001 \quad 38.4813 \mathrm{~m}^{2} / \mathrm{g}$

Single-point adsorption total pore volume of $0.33003 \mathrm{~cm}^{3} / \mathrm{g}$

the pores (pores less than $2988.714 \AA$

diameter at $\mathrm{P} / \mathrm{P}_{\mathrm{o}}=0.993559$ )

BET surface area

$39.9930 \mathrm{~m}^{2} / \mathrm{g}$

Adsorption average pore width (4V/A by $33.00897 \mathrm{~nm}$

BET)

t-plot external surface area $\quad 39.1537 \mathrm{~m}^{2} / \mathrm{g}$

t-plot micropore area

$0.8393 \mathrm{~m}^{2} / \mathrm{g}$

t-plot micropore volume $\quad 0.000187 \mathrm{~cm}^{3} / \mathrm{g}$

BJH adsorption cumulative surface area of $33.553 \mathrm{~m}^{2} / \mathrm{g}$ pores between 17-3000 $\AA$ diameter

BJH adsorption average pore width (4V/A by $38.9751 \mathrm{~nm}$ $\mathrm{BET})$

BJH desorption cumulative surface area of $36.7427 \mathrm{~m}^{2} / \mathrm{g}$ pores between 17-3000 $\AA$ diameter

BJH desorption average pore width (4V/A by $35.8733 \mathrm{~nm}$ BET)

(b') Magnetic properties of MChi

\begin{tabular}{ll}
\hline Parameters & Values \\
\hline Coercivity $(\mathrm{Hc})$ & $54.507 \mathrm{Oe}$ \\
Magnetization (Ms) & $28.645 \mathrm{emu} / \mathrm{g}$ \\
Retentivity (M) & $2.9258 \mathrm{emu} / \mathrm{g}$ \\
\hline
\end{tabular}

172 Fig. 3 (a) $\mathrm{N}_{2}$ ad-/de-sorption isotherm, (a') Summary of the BET analyses (b) Magnetization curve (b') Magnetic properties of MChi 
174 of $\mathrm{Fe}_{3} \mathrm{O}_{4}$ shows the peaks at $2 \theta$ of 32.42, 34.88, 40.08, 48.63, 53.22, 56.8, 61.63, 63.15 and 71.2

175 which are agreeing with the standard $\mathrm{Fe}_{3} \mathrm{O}_{4}$ XRD pattern, ascertain that the $\mathrm{Fe}_{3} \mathrm{O}_{4}$ are inverse 176 cubic spinel structure (Kazeminezhad and Mosivand 2014; Zhu et al. 2017). An almost similar

177 XRD pattern of MChi was noticed, which suggests that the presence of Chi does not change the 178 crystallinity of $\mathrm{Fe}_{3} \mathrm{O}_{4}$.

179 The thermogravimetric analysis (TGA) plot of MChi illustrated in Fig. 4b presented a 180 weight loss of $16 \%$ below $240{ }^{\circ} \mathrm{C}$, referring to the loss of moisture and thereafter a rapid and 181 major weight loss of about $62 \%$ in between $240-540{ }^{\circ} \mathrm{C}$, accounted for the degeneration of Chi 182 chain and cleavage of the ether linkage in the Chi backbone (Cao et al. 2014; Cabuk et al. 2014).

183 The average mass losses of MChi was estimated to be about $84 \%$ at degradation temperature of $184700{ }^{\circ} \mathrm{C}$. 

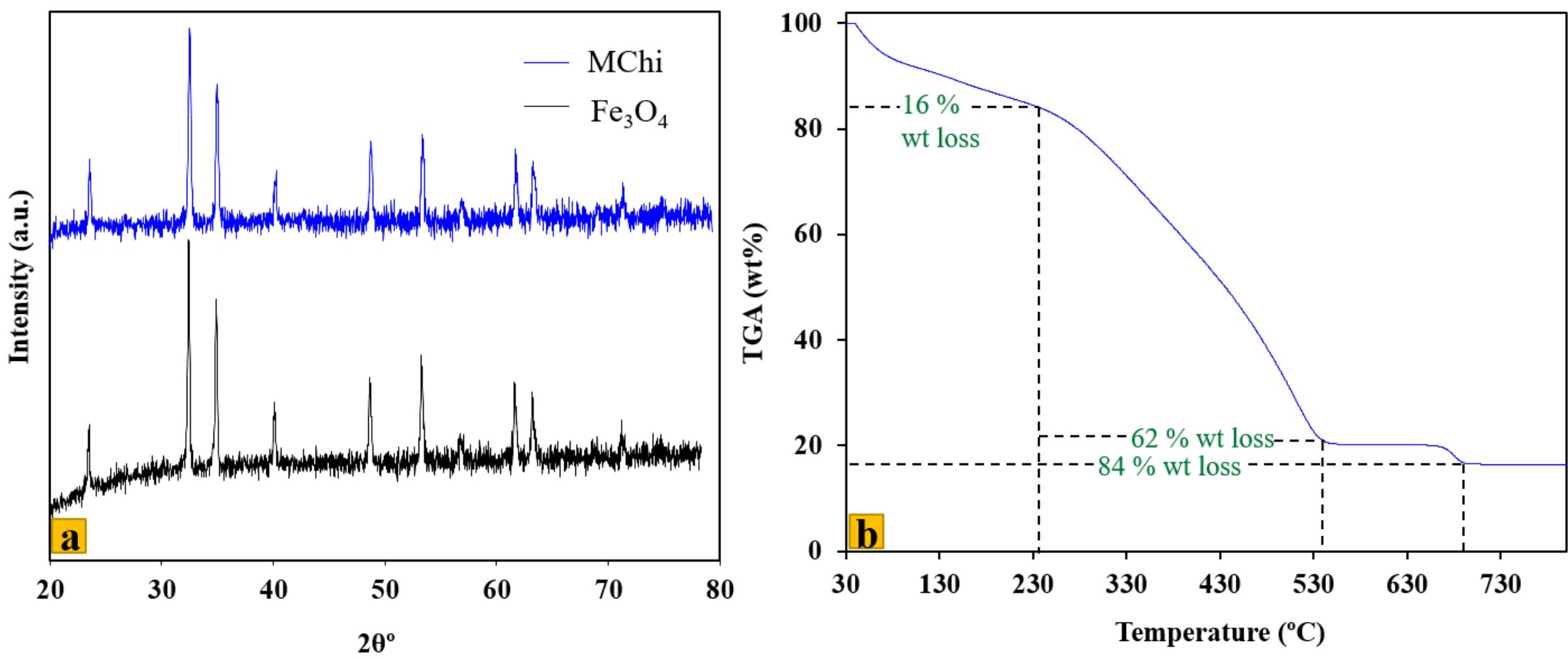

Fig. 4 XRD patterns of $\mathrm{Fe}_{3} \mathrm{O}_{4}$, and MChi (b)TGA plot of MChi 


\section{Adsorption studies}

188

189

190

191

192 193

\section{Effect of pH of the solution}

The initial $\mathrm{pH}$ of the dye solution is an essential controlling parameter in the adsorption process because the ionic properties and structure of dye molecules may vary with varying the $\mathrm{pH}$ of the solution. Fig. 5 shows the adsorption profiles of $\mathrm{MG}$ and $\mathrm{MB}$ onto the $\mathrm{MChi}$ at different $\mathrm{pH}$ values. The outcomes showed that the solution $\mathrm{pH}$ had a significant effect on the adsorption of dye molecules and presented that by increasing the $\mathrm{pH}$ of the solution from $4-11$, the adsorption capacity (removal percent) of MChi was risen significantly from 17.21 to $28.93 \mathrm{mg} \mathrm{g}^{-1}$ (57.40 to 98.20 \%) for MG and 26.00 to $49.07 \mathrm{mg} \mathrm{g}^{-1}$ (52.01 to $\left.97.90 \%\right)$ for MB. These adsorption trends of both the dyes can be better explained by closer inspection of $\mathrm{pHpc}$, which was found to be 6.6 as shown in inset inset-Fig. 5. This figure displays that at $\mathrm{pH}$ lesser than $\mathrm{pHpc}$ induces a totally positive charge over the surface of MChi, and causes competitive adsorption between $\mathrm{H}^{+}$ions and cationic dye molecules in the solution for the binding sites. Moreover, the number of positively charged adsorbing sites increased with the decrease of $\mathrm{pH}$, which electrostatically repels the cationic dye molecules. While in the alkaline regime $(\mathrm{pH}>\mathrm{pHpc})$, the adsorption capacity was increases significantly, which might be owing to the deprotonation of superficial functional groups which strongly attract the cationic moiety of MG and MB molecules. It is clear that the alkaline $\mathrm{pH}$ of the dye solution favors the adsorption of cationic dyes onto the MChi. Therefore, the $\mathrm{pH} 7$ for both MG and MB were chosen for further studies. 


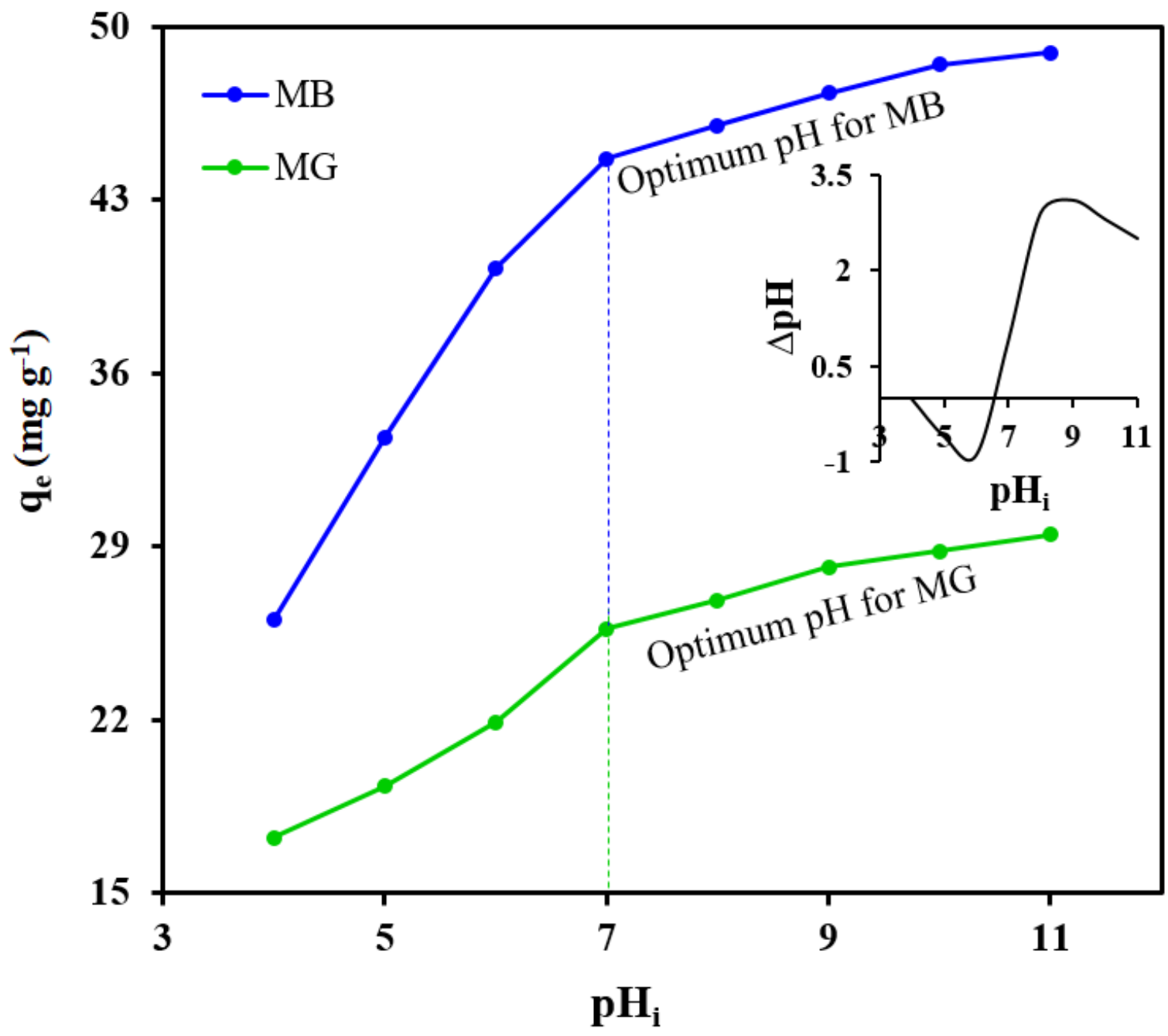

207 Fig. 5 Effect of pH on adsorption capacity of MChs (inset-point of zero charge of MChi) 208 Effect of adsorbent dose

210 The adsorbent dose is a significant factor for determining the adsorption capacity of an 211 adsorbent. The effect of different MChi doses of 0.4 to $6 \mathrm{~g} \mathrm{~L}^{-1}$ on the adsorption of MG and MB 212 onto the MChi was evaluated at an initial dye concentration of $50 \mathrm{mg} \mathrm{g}^{-1}$, and the fallouts are 213 shown in Fig. 6. This figure reveals that by increasing the quantity of MChi dose $\left(0.4\right.$ to $\left.6 \mathrm{~g} \mathrm{~L}^{-1}\right)$, 
214 the percentage removal of both MG (53.84 to $93.73 \%)$ and MB (66.80 to $96.20 \%)$ was

215 increased, which may be accredited to the availability of large surface area and easy accessibility

216 of additional sorption sites. On the contrary, the adsorbate loading capacity per gram of

217 adsorbent dose declines evidently from 80.76 to $9.37 \mathrm{mg} \mathrm{g}^{-1}$ for $\mathrm{MG}$ and 100.19 to $9.62 \mathrm{mg} \mathrm{g}^{-1}$

218 for $\mathrm{MB}$ with the increase of adsorbent dose from 0.4 to $6.0 \mathrm{~g} \mathrm{~L}^{-1}$, which was because at a higher

219 amount of MChi, the available adsorbate molecules were inadequate to cover all the active

220 adsorbing sites, thereby the adsorbing sites could not attain saturation at higher MChi dose. An

221 insufficient amount of adsorbent or overdosing would results in less adsorption or high cost,

222 thus, for economic adsorption and also by considering the influence on removal efficiency and

223 sorption capacity, compromising MChi dosage of 2.0 and $1.2 \mathrm{~g} \mathrm{~L}^{-1}$ for the adsorption of MG and

$224 \mathrm{MB}$, respectively were selected for further adsorption experiments. 


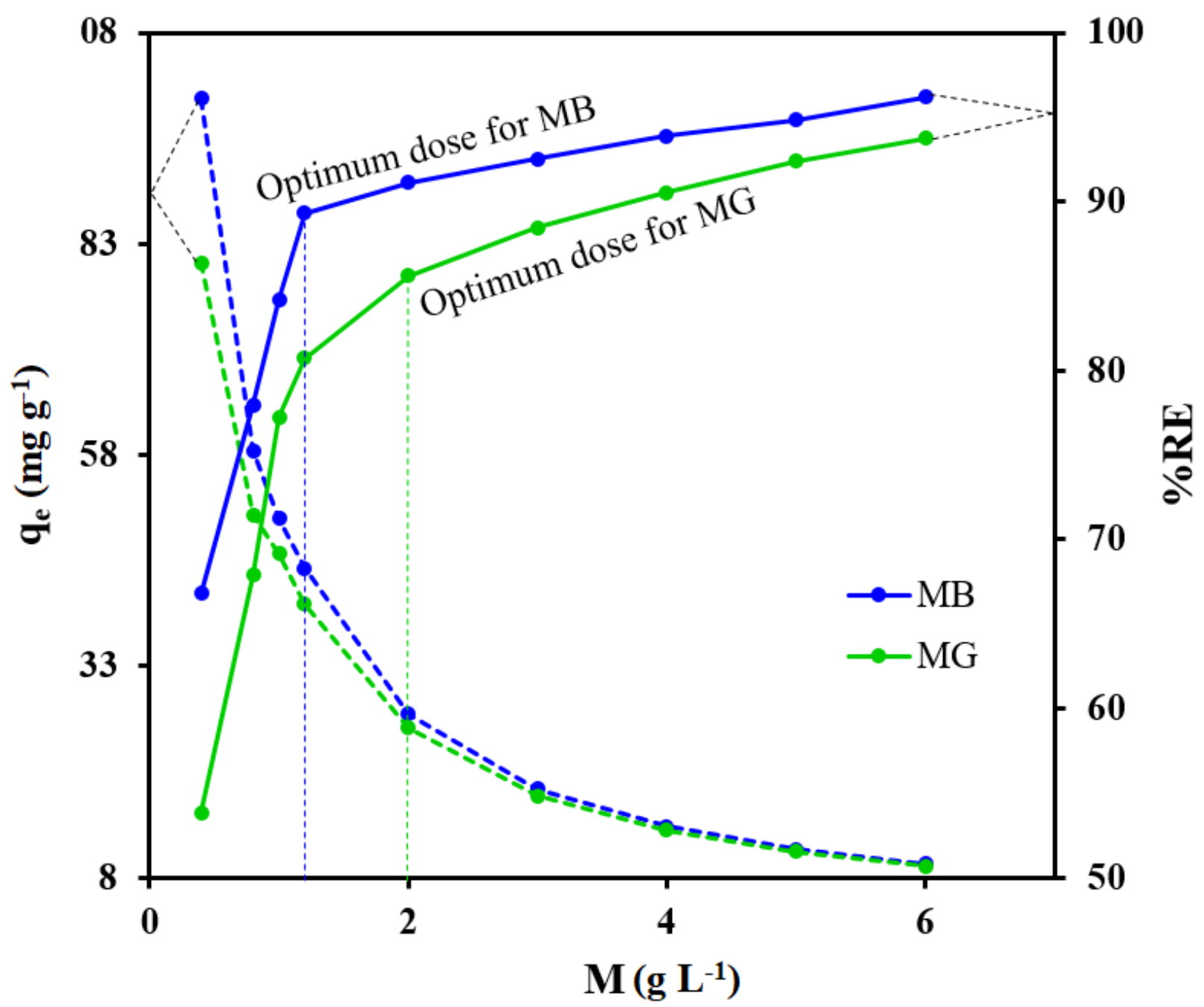

Fig. 6 Effect of MChs dose on adsorption capacity $\left(\mathrm{q}_{\mathrm{e}}\right)$ and removal efficiency (\% RE) of MChi

\section{Effect of contact time and kinetic study}

229 The MG and MB uptake was studied with respect to time in order to observe an appropriate 230 interaction time at which the adsorption achieves equilibrium. Fig. 7 demonstrates the influence

231 of contact time on the adsorption of MG and MB by MChi. It is apparent from this figure that the 232 adsorption of both MG and MB was increased initially up to 30 min at a very speedy rate due to 233 the vacant or easy availability of the reaction sites on the external surface of MChi and with the 
234 extension of adsorption time, there was a transitional phase in which the uptake process was 235 slowed down and achieve equilibrium within 210 and $180 \mathrm{~min}$ for MG and MB, respectively.

236 The slow adsorption rate at the later stage was probably owing to the lessening in the availability

237 of the remaining active sites and also may be due to the long-range diffusion of adsorbate species

238 into the micropores of the MChi which needs a greater time to achieve equilibrium (Du et al.

239 2014). It is also evident from the Fig. 7 that the amount of MG and MB adsorbed onto the MChi

240 increased with an enhancement in initial dye concentration. It is due to higher driving force for

241 mass transfer of dye molecules from the liquid phase to the solid phases. Also, the escalation in

242 initial concentration of dye increases the interaction between adsorbate and adsorbent and thus,

243 increases the adsorption uptake of MG and MB dye molecules.

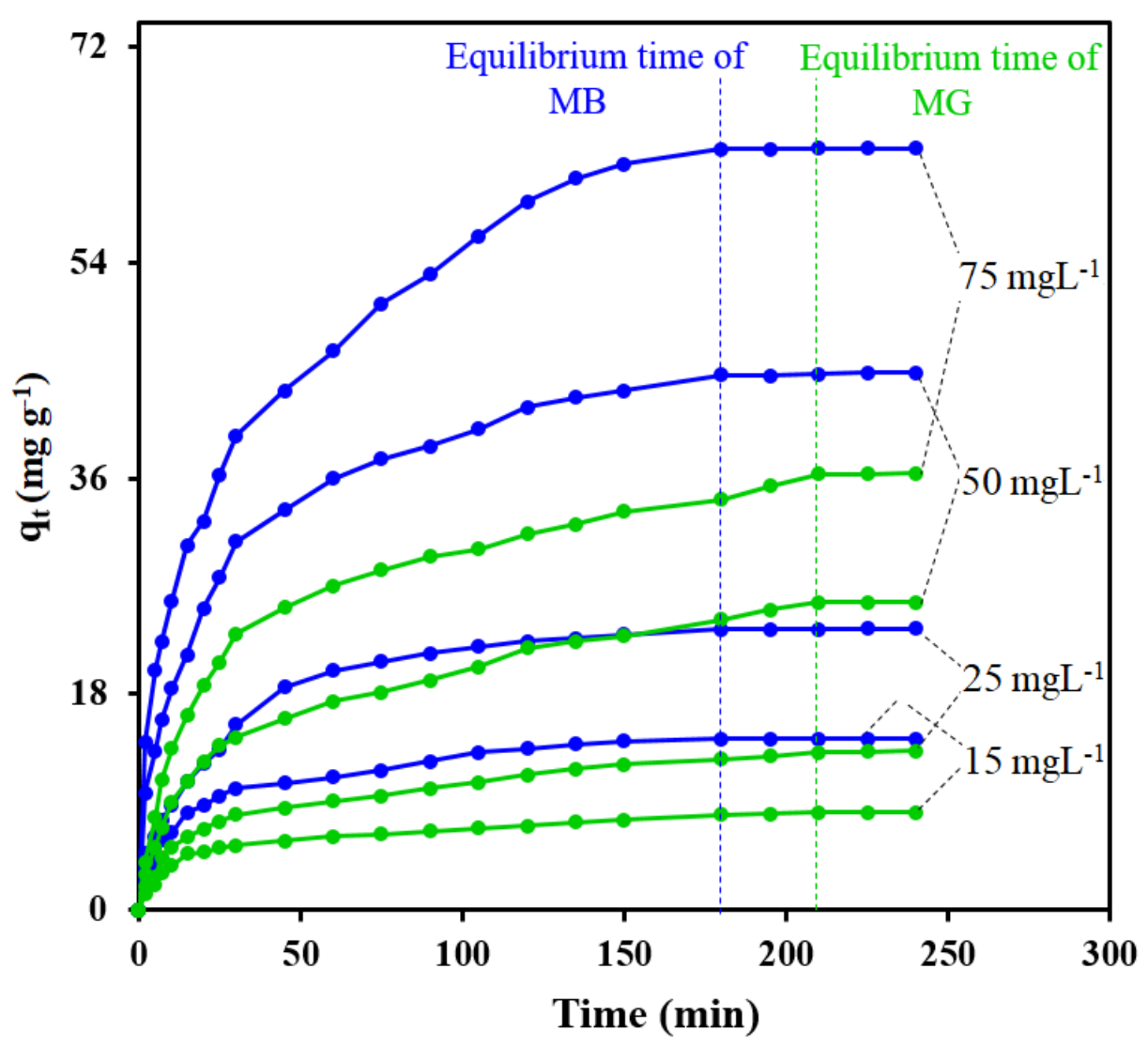

245 Fig. 7 Effect of contact time on adsorption capacity of MChi 
246 The time-dependent kinetic data accompanying with the adsorption of both the dyes were

247 analyzed with pseudo- $\mathrm{I}^{\text {st }}$-order and pseudo-II ${ }^{\mathrm{nd}}$-order models. These two models are described by

248 Eqs. 4 and 5, respectively (Mashkoor and Nasar 2020a).

$249 \ln \left(q_{e}-q_{t}\right)=\ln q_{e}-K_{1} t$

$250 \quad \frac{\mathrm{t}}{\mathrm{q}_{\mathrm{t}}}=\frac{1}{\mathrm{~K}_{2} \mathrm{q}_{\mathrm{e}}^{2}}+\frac{\mathrm{t}}{\mathrm{q}_{\mathrm{e}}}$

252 where, $\mathrm{K}_{1}\left(\mathrm{~min}^{-1}\right)$, and $\mathrm{K}_{2}\left(\mathrm{~g} \mathrm{~min}^{-1} \mathrm{mg}^{-1}\right)$ are the rate constants of the pseudo- $1^{\text {st }}$ order, and 253 pseudo- $2^{\text {nd }}$-order kinetic model, respectively. The kinetic parameters and correlation coefficients $254\left(\mathrm{R}^{2}\right)$ obtained by fitting the time-dependent experimental data for the adsorption of MG and MB 255 onto the MChi are summarized in Table 1 . The $\mathrm{R}^{2}$ values that were obtained for the pseudo-II ${ }^{\mathrm{nd}}$ 256 order model were higher than those of the pseudo- $\mathrm{I}^{\mathrm{st}}$-order. Furthermore, the calculated and 257 experimental values of the adsorption capacity, $\mathrm{q}_{\mathrm{e}}$, were almost the same at all initial dye 258 concentration. These outcomes specify that the pseudo-II ${ }^{\text {nd }}$-order kinetic model offers a good 259 correlation for the elimination of both MG and MB onto MChi, as shown in Fig. 8. The rate260 limiting step might be chemisorption comprising valence forces by sharing or exchange of 261 electrons between the adsorbate and adsorbent (Bayramoglu et al. 2009). Further, as indicated 262 from Table 1, the values of pseudo-II ${ }^{\text {nd }}$-order rate constant were found to be decreased with the 263 increase of initial concentration of dye for both the system. This shows that the adsorption of 264 MG and MB onto the MChi were more favorable for low initial concentration of dye. 


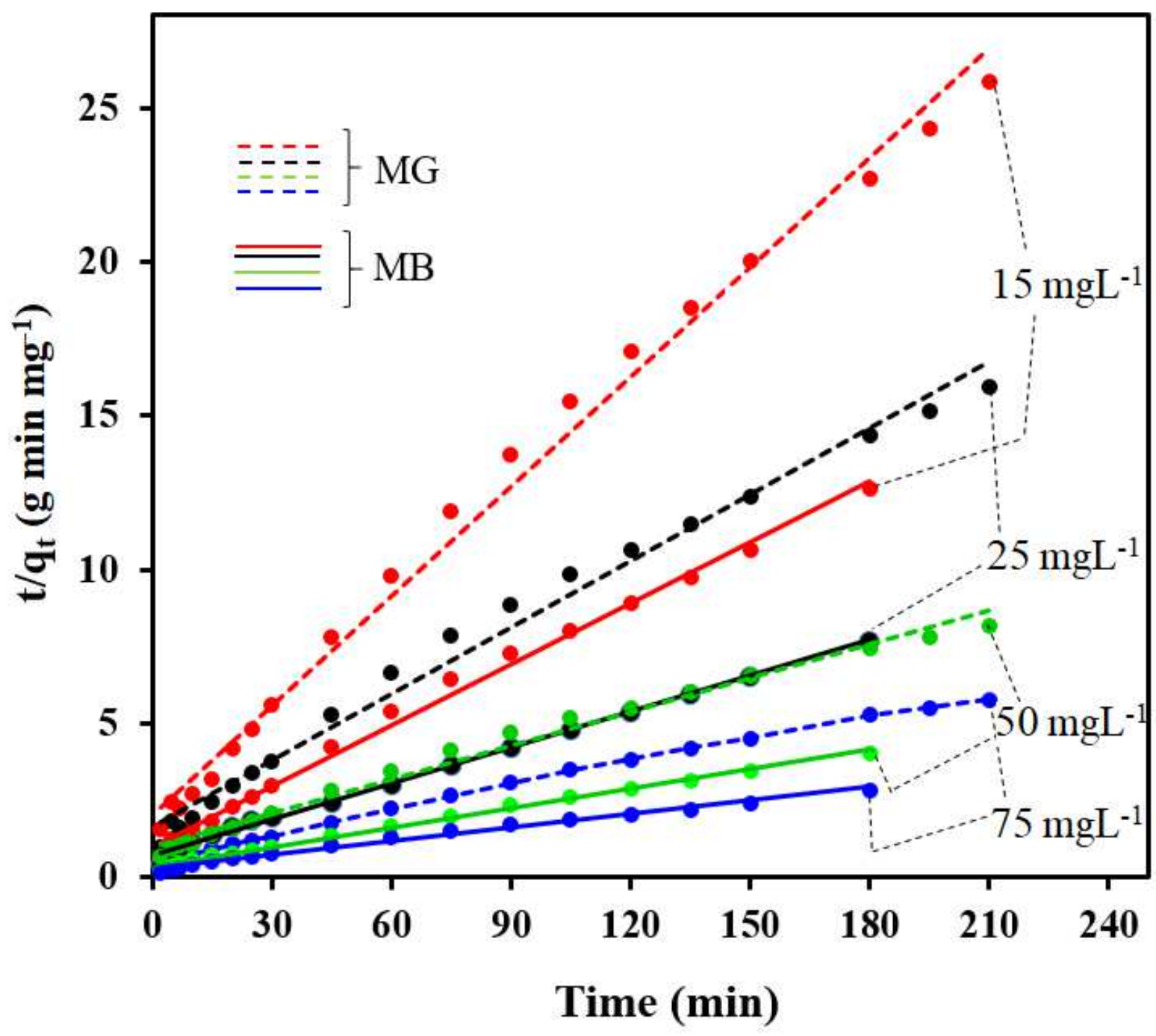

266

Fig. 8 Pseudo-II ${ }^{\text {nd }}$-order plot for the MG and MB adsorption onto the MChi

267

268

Table 1 Kinetic results for the MG and MB adsorption onto MChi (reaction conditions: $\mathrm{C}_{\mathrm{o}}=50$

$269 \mathrm{mg} \mathrm{L}-1$, MChi dose $=2 \mathrm{~g} \mathrm{~L}^{-1}, \mathrm{pH}=7$, and $\mathrm{T}=303 \mathrm{~K}$ for $\mathrm{MG}$ and $\mathrm{C}_{\mathrm{o}}=50 \mathrm{mg} \mathrm{L}^{-1}$, MChi dose $=$

$2701.2 \mathrm{~g} \mathrm{~L}^{-1}, \mathrm{pH}=7$, and $\mathrm{T}=303 \mathrm{~K}$ for $\mathrm{MB}$ )

271 


\begin{tabular}{|c|c|c|c|c|c|c|c|}
\hline $\mathrm{C}_{\mathrm{o}}$ & 15 & & & & & 75 & \\
\hline Dye & MG & & MB & $\mathrm{MG}$ & MB & MG & $\mathrm{MB}$ \\
\hline
\end{tabular}

\section{Pseudo- ${ }^{\text {st }}$-order}

\begin{tabular}{lllllllll}
\hline $\mathrm{K}_{1}$ & 0.017 & 0.0232 & 0.0156 & 0.0272 & 0.0151 & 0.0205 & 0.0149 & 0.0214 \\
& & & & & & & & \\
qexp & 8.12 & 14.269 & 13.16 & 23.39 & 25.64 & 44.64 & 36.37 & 63.46 \\
& & & & & & & & \\
qcal & 5.717 & 10.515 & 10.067 & 16.114 & 20.72 & 31.630 & 26.136 & 50.7697 \\
$\mathrm{R}^{2}$ & 0.9356 & 0.9536 & 0.9694 & 0.9831 & 0.9564 & 0.9876 & 0,9694 & 0.9644 \\
\hline
\end{tabular}

\section{Pseudo-2 ${ }^{\text {nd }}$-order}

\begin{tabular}{lllllllll}
\hline $\mathrm{K}_{2}$ & $6.878 \times 10^{-3}$ & $4.3113 \times 10^{-3}$ & $3.1729 \times 10^{-3}$ & $2.157 \times 10^{-3}$ & $1.3848 \times 10^{-3}$ & $1.308 \times 10^{-3}$ & $1.1897 \times 10^{-3}$ & $7.7702 \times 10^{-4}$ \\
qexp & 8.12 & 14.269 & 13.16 & 23.39 & 25.64 & 44.64 & 36.37 & 63.46 \\
q $_{\text {cal }}$ & 8.446 & 15.175 & 13.908 & 25.707 & 27.322 & 47.393 & 38.462 & 68.027 \\
$\mathrm{R}^{2}$ & 0.9932 & 0.9958 & 0.9899 & 0.9973 & 0.989 & 0.9965 & 0.996 & 0.9902
\end{tabular}

\section{IPD}

\begin{tabular}{lcccccccc}
\hline $\mathrm{K}_{\mathrm{id}}$ & 0.4443 & 0.9039 & 0.7803 & 1.6543 & 1.5908 & 2.8906 & 2.2107 & 4.1309 \\
$\mathrm{~B}$ & 2.2097 & 3.6253 & 2.5748 & 4.4337 & 3.844 & 10.327 & 6.8808 & 13.137 \\
& & & & & & & & \\
$\mathrm{R}^{2}$ & 0.9032 & 0.9056 & 0.9519 & 0.9248 & 0.9612 & 0.9383 & 0.9236 & 0.9764
\end{tabular}


274 onto the MChi, the intraparticle diffusion model (IPD) was employed to evaluate the time-

275 dependent experimental data, which can be given by the following equation (Mashkoor and 276 Nasar 2019a):

$277 \quad \mathrm{q}_{\mathrm{t}}=\mathrm{K}_{\mathrm{id}} \sqrt{t}+\mathrm{B}$

279 where, $\mathrm{B}$ is the intercept $\left(\mathrm{mg} \mathrm{g}^{-1}\right)$, which provides the information about the thickness of the 280 boundary layer, i.e., the larger intercept, the greater is the boundary layer effect. The $\mathrm{k}_{\mathrm{id}}$ is the 281 IPD rate constant $\left(\mathrm{mg} \mathrm{g}^{-1} \mathrm{~min}^{-1 / 2}\right)$, which can be calculated from the slope of the $\mathrm{q}_{\mathrm{t}}$ versus $\mathrm{t}^{1 / 2}$ plot 282 (figure not shown). The IPD plot consisted of three sequential steps: the initial step of the plot 283 representing the surface adsorption and rapid external diffusion and shows the existence of the 284 boundary layer (Wang et al. 2015). The second stage corresponds to the particle diffusion, where 285 adsorbate molecules traverse within the pores of the adsorbent, and the third region is the 286 equilibrium approaching stage (Mane and Vijay Babu 2013; Tan and Hameed 2017). If the

287 regression of $\mathrm{qt}_{\mathrm{t}} \mathrm{vs} \mathrm{t}^{1 / 2}$ is linear and passes through the origin, then IPD is the sole rate-controlling 288 step. The deviation of straight lines from the origin indicates that IPD is not the only rate289 limiting step. It can likewise be seen from the table that intercept B, increases with initial dye 290 concentration indicating the enhancement in the thickness and role of the boundary layer [36]. 291 Moreover, the $\mathrm{k}_{\mathrm{id}}$ values for the elimination of MB onto the MChi were higher than those for 292 MG, signifying more driving force in the former (Sewu et al. 2019).

\section{Isotherm study}


294 Adsorption isotherm was used to describe the interactive behavior and the distribution of 295 adsorbed molecules between the solution and adsorbent when the adsorption process achieves 296 equilibrium and is essential in the modeling of the adsorption system. Three different isotherms, 297 viz., Langmuir, Freundlich, and Temkin have been employed to model the experimental data. 298 The Langmuir model stated a structurally homogeneous adsorbent and monolayer coverage of 299 adsorbate over the surface of adsorbent with no interaction between the adsorbate molecules. In 300 this respect, once an adsorbate species occupies a site, no further adsorption can take place at that 301 site. This model is expressed mathematically according to the following linear equation (Zayed 302 et al. 2018; Mashkoor and Nasar 2020c).

$$
\frac{1}{q_{e}}=\frac{1}{q_{m} K_{L} C_{e}}+\frac{1}{q_{m}}
$$

304 Where $\mathrm{K}_{\mathrm{L}}\left(\mathrm{L} \mathrm{mg}^{-1}\right)$ is the Langmuir constant, and $\mathrm{q}_{\mathrm{m}}\left(\mathrm{mg} \mathrm{g}^{-1}\right)$ is the maximum monolayer 305 sorption capacity. An essential characteristic of the Langmuir isotherm can be defined by a 306 dimensionless quantity, $\mathrm{R}_{\mathrm{L}}\left(=\frac{1}{1+\mathrm{K}_{\mathrm{L}} \mathrm{C}} \mathrm{O}\right)$ known as separation factor, the values of which show that 307 the adsorption to be either favorable $(0-1)$, unfavorable $(>1)$ or linear $(1)$, or irreversible $(0)$. multilayer adsorption and mathematically expressed in the linear form (Foo and Hameed 2010; Mashkoor and Nasar 2020c):

$311 \quad \ln \mathrm{q}_{\mathrm{e}}=\frac{1}{\mathrm{n}} \ln \mathrm{C}_{\mathrm{e}}+\ln \mathrm{K}_{\mathrm{F}}$

312 Where, $\mathrm{K}_{\mathrm{f}}\left(\mathrm{mg} \mathrm{g}^{-1}\right)$ shows adsorption capacity, and $\mathrm{n}$ is an empirical factor associated to the 313 intensity of adsorption, which varies with the heterogeneity of the adsorbing material. The larger 314 value of the $\mathrm{n}$, favors the adsorption. 
316 linear reduction in the heat of adsorption rather than in logarithmic form. This model can be

317 represented by linear form as (Foo and Hameed 2010):

$$
\mathrm{q}_{\mathrm{e}}=\mathrm{BlnC}_{\mathrm{e}}+\mathrm{B} \ln \mathrm{K}_{\mathrm{T}}
$$

319

320

321

322

323

324

325

326

327

328

329

330

331

332

333

334

335

where, $\mathrm{K}_{\mathrm{T}}\left(\mathrm{L} \mathrm{g}^{-1}\right)$ is the equilibrium binding constant related to the maximum binding energy, and $\mathrm{B}(=\mathrm{RT} / \mathrm{b}), \mathrm{b}\left(\mathrm{J} \mathrm{mol}^{-1}\right)$ is the Temkin isotherm constants. $\mathrm{R}\left(=8.314 \mathrm{~J} \mathrm{~K}^{-1} \mathrm{~mol}^{-1}\right)$ is the universal gas constant and $\mathrm{T}(\mathrm{K})$ is the absolute temperature.

The isotherm parameters, as obtained by fitting the equilibrium parameters for the adsorption of MG and MB onto the MChi, are given in Table 2. In the light of higher values of $\mathrm{R}^{2}$, the Langmuir model is proposed to be best fit for both the systems (MG/MChi and $\mathrm{MB} / \mathrm{MChi}$ ) at all temperatures implying monolayer coverage of MG and MB molecules onto the surface of MChi as illustrated in Fig. 9. Moreover, the values of $\mathrm{q}_{\mathrm{m}}$ increase with the increase of temperature, signifying an endothermic nature of the existing adsorption process. Besides, the values of $R_{L}$ at an initial MG and MB concentration of $15,25,50,75$, and $100 \mathrm{mg} \mathrm{L}^{-1}$ were found to be $0.3705,0.2609,0.1500,0.1053$, and 0.0811 for MG and $0.1781,0.1151,0.0611$, 0.0416 and 0.0315 for $\mathrm{MB}$, respectively at $303 \mathrm{~K}$. These values are in the range of 0 to 1 , which points out the favorability of the adsorption process for both the system.

Some of the literature work on the elimination of MG (Bekçi et al. 2008; Debrassi et al. 2012; Li et al. 2015; Naseeruteen et al. 2018; Arumugam et al. 2019; Hasan et al. 2020) and MB (Yan et al. 2013; Zeng et al. 2015; Cho et al. 2015; Marrakchi et al. 2016; Rahmi et al. 2019; Mokhtar et al. 2020) onto the chitosan-based composites are listed in Table 3. This table demonstrates the satisfactory performance of the present adsorbent, MChi. 


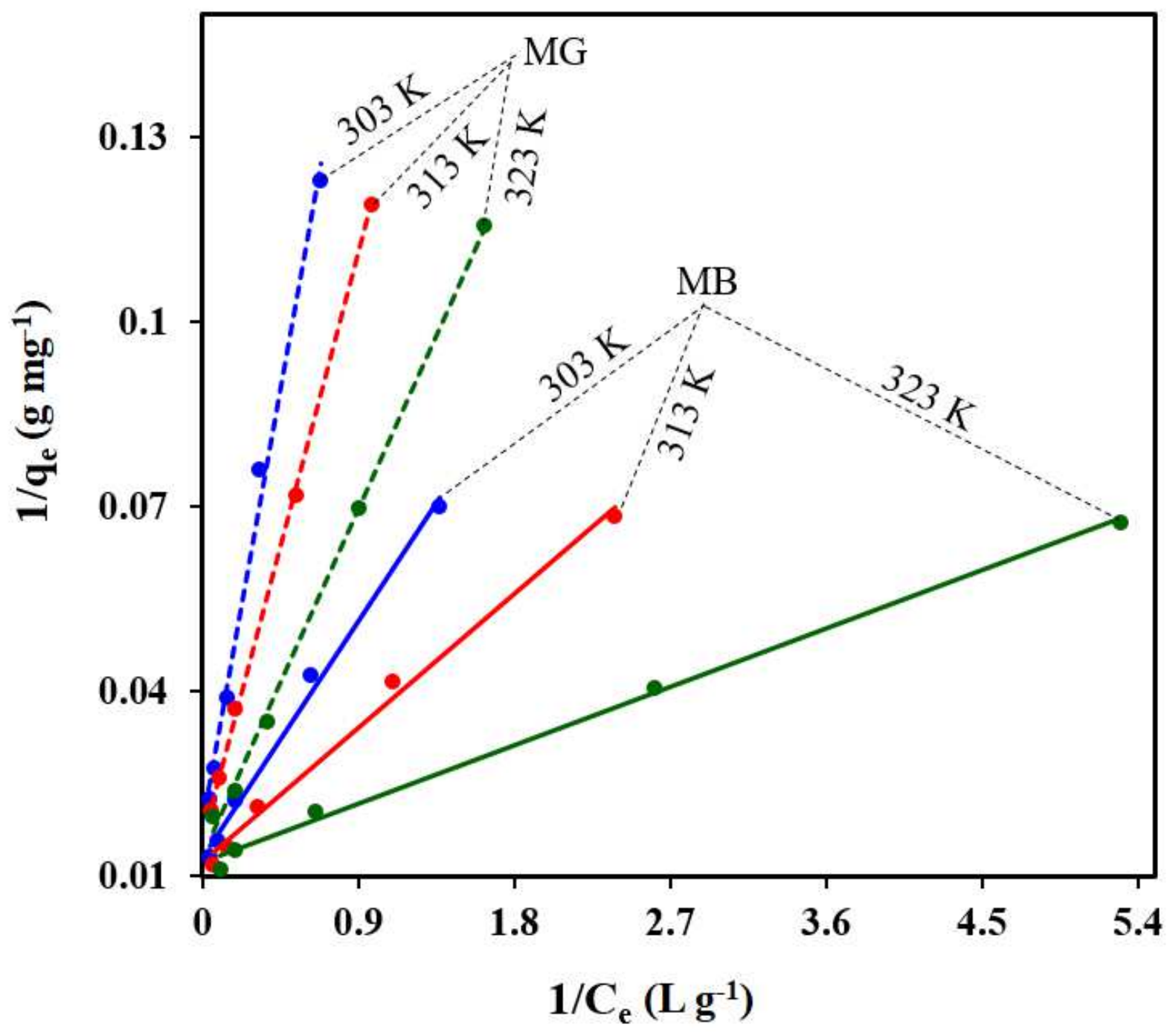

Fig. 9 Langmuir model for the MG and MB adsorption onto the MChi

Table 2 Isotherm parameters for the MG and MB adsorption onto MChi at different temperature

341 (reaction condition: $\mathrm{MChs}$ dose $=2 \mathrm{~g} \mathrm{~L}^{-1}, \mathrm{t}=210 \mathrm{~min}, \mathrm{pH}=7$ for $\mathrm{MG}$ and $\mathrm{MChi}$ dose $=1.2 \mathrm{~g} \mathrm{~L}^{-}$

$342 \quad 1, t=180 \min , \mathrm{pH}=7$ for $\mathrm{MB})$

\begin{tabular}{l|ll|ll|ll}
\hline \multicolumn{2}{c|}{303} & \multicolumn{2}{c|}{313} & \multicolumn{2}{c}{323} \\
\hline Adsomperature (K) & MG & MB & MG & MB & MG & MB \\
\hline
\end{tabular}




\begin{tabular}{lllllll}
\hline $\mathrm{q}_{\mathrm{m}}$ & 55.8659 & 76.3359 & 62.893 & 81.3008 & 74.0741 & 82.645 \\
& & & & & & \\
$\mathrm{~K}_{\mathrm{L}}$ & 0.113291 & 0.30751 & 0.150711 & 0.508265 & 0.2160 & 1.141511 \\
$\mathrm{R}^{2}$ & 0.9924 & 0.9921 & 0.9995 & 0.9931 & 0.9984 & 0.994
\end{tabular}

Freundlich

$\begin{array}{lllllll}\mathrm{N} & 1.64258 & 2.0333 & 1.6761 & 2.05719 & 1.80473 & 2.2727 \\ \mathrm{~K}_{\mathrm{F}} & 6.79237 & 17.9376 & 9.0784 & 24.320 & 13.50419 & 34.8168 \\ \mathrm{R}^{2} & 0.9829 & 0.9854 & 0.9859 & 0.9804 & 0.9279 & 0.9794\end{array}$

Temkin

$\begin{array}{lllllll}\mathrm{B} & 13.067 & 18.371 & 13.703 & 19.411 & 13.585 & 18.430 \\ \mathrm{~K}_{\mathrm{T}} & 1.07636 & 2.53436 & 1.58636 & 4.292657 & 3.008924 & 10.34738 \\ \mathrm{R}^{2} & 0.9863 & 0.9894 & 0.9897 & 0.9895 & 0.9797 & 0.9837\end{array}$

344 Table 3 Comparison of Langmuir factors for the adsorption of MG and MB on the Chi based 345 adsorbents

\begin{tabular}{lllll}
\hline Adsorbent & $\mathrm{q}_{\mathrm{m}}\left(\mathrm{mg} \mathrm{g}^{-1}\right)$ & $\mathrm{K}_{\mathrm{L}}\left(\mathrm{L} \mathrm{mg}^{-1}\right)$ & $\mathrm{R}^{2}$ & References \\
\hline Malachite green & & & & \\
\hline $\begin{array}{l}\text { Coir pith activated } \\
\text { carbon/chitosan/sodium dodecyl } \\
\text { sulphate }\end{array}$ & 4.8 & 0.1 & 0.999 & (Arumugam et al. \\
$\begin{array}{l}\text { Polyacrylamide-g-chitosan } \gamma-\mathrm{Fe}_{2} \mathrm{O}_{3} \\
\text { 2019) }\end{array}$ & 62.89 & 0.25 & 0.990 & (Hasan et al. 2020) \\
& 93.55 & 0.41 & 0.982 & (Bekçi et al. 2008) \\
Chitosan bead & & & & \\
\hline
\end{tabular}




\begin{tabular}{|c|c|c|c|c|}
\hline Chitosan ionic liquid beads & 8.07 & -12.399 & 0.998 & $\begin{array}{l}\text { (Naseeruteen et al. } \\
\text { 2018) }\end{array}$ \\
\hline Polyurethane/chitosan composite & 16.67 & $0.78 *$ & 0.9756 & (Li et al. 2015) \\
\hline \multicolumn{5}{|l|}{ foam } \\
\hline $\begin{array}{l}\text { N-benzyl-O- } \\
\text { carboxymethylchitosan magnetic } \\
\text { nanoparticles }\end{array}$ & 99.82 & 0.474 & 0.927 & $\begin{array}{l}\text { (Debrassi et al. } \\
\text { 2012) }\end{array}$ \\
\hline MChi & 55.87 & 0.11329 & 0.9924 & Present work \\
\hline
\end{tabular}

\section{Methylene blue}

\begin{tabular}{|c|c|c|c|c|}
\hline $\begin{array}{l}\mathrm{H}_{2} \mathrm{SO}_{4} \text { crosslinked magnetic } \\
\text { chitosan }\end{array}$ & 20.408 & 0.018 & 0.998 & (Rahmi et al. 2019) \\
\hline Chitosan/clay/ $/ \mathrm{Fe}_{3} \mathrm{O}_{4}$ & 45.1 & 0.1897 & 0.907 & (Cho et al. 2015) \\
\hline Crosslinked chitosan/sepiolite & 40.986 & 0.680 & 0.915 & $\begin{array}{l}\text { (Marrakchi et al. } \\
\text { 2016) }\end{array}$ \\
\hline $\begin{array}{l}\text { Magadiite-chitosan composite } \\
\text { beads }\end{array}$ & 40.01 & 0.014 & 0.995 & $\begin{array}{l}\text { (Mokhtar et al. } \\
\text { 2020) }\end{array}$ \\
\hline Chitosan/organic rectorite & 24.69 & 0.242 & 0.999 & (Zeng et al. 2015) \\
\hline $\begin{array}{l}\text { Chitosan magnetic composite } \\
\text { microspheres }\end{array}$ & 33.60 & $4.26 \times 10^{2}$ & 0.995 & (Yan et al. 2013) \\
\hline MChi & 76.34 & 0.3075 & 0.9921 & Present work \\
\hline
\end{tabular}


349 To understand the influence of temperature on the adsorption of MG and MB onto the MChi, the 350 adsorption experiments were accompanied at 303, 313, 323 and $333 \mathrm{~K}$. The thermodynamic

351 factors such as Gibb's free energy change $(\Delta \mathrm{G})$, enthalpy change $(\Delta H)$, and entropy change $(\Delta S)$ 352 were measured by employing the following Van’t Hoff equation (Mashkoor and Nasar 2019b; 353 Ahmed et al. 2020).

$354 \Delta \mathrm{G}=-\mathrm{RT} \ln \mathrm{K}_{\mathrm{c}}$

$355 \quad \ln \mathrm{K}_{\mathrm{C}}=\frac{-\Delta \mathrm{G}}{\mathrm{RT}}=\frac{-\Delta \mathrm{H}}{\mathrm{RT}}+\frac{\Delta \mathrm{S}}{\mathrm{R}}$

356 where, $\mathrm{K}_{\mathrm{c}}$ represents equilibrium constant. The parameters $\Delta \mathrm{H}$ and $\Delta \mathrm{S}$ were calculated 357 respectively from the slope and intercept of van't Hoff plot of $\ln K_{c}$ versus 1/T (figure not given). 358 All the values of the thermodynamic parameters are listed in Table 4 . The negative values of $\Delta \mathrm{G}$ 359 for both $\mathrm{MG}$ and $\mathrm{MB}$ over the entire temperature range (303 to $333 \mathrm{~K}$ ) demonstrated the 360 underlying spontaneity and confirmed the feasibility of the adsorption process. In other words, a 361 large negative value of $\Delta \mathrm{G}$ infers a greater driving force of adsorption, ensuing in improved 362 adsorption capacity. From Table 4 , the $\Delta \mathrm{G}$ value was resulted to be more negative at higher 363 temperatures, suggesting that the process for the elimination of both MG and MB was more 364 spontaneous at higher temperatures. In fact, $\Delta \mathrm{G}$ for chemisorption is greater than that for 365 physisorption. The former is between -80 and $-400 \mathrm{~kJ} \mathrm{~mol}^{-1}$, and the latter is between -20 to $0 \mathrm{~kJ}$ $366 \mathrm{~mol}^{-1}$ (Kuo et al. 2008; Tehrani-Bagha et al. 2011). In this research, the negative values of $\Delta \mathrm{G}$ 367 for MG range from 7.24 to $14.08 \mathrm{~kJ} \mathrm{~mol}^{-1}$ and 6.44 to $11.29 \mathrm{~kJ} \mathrm{~mol}^{-1}$ for $\mathrm{MB}$, representing that 368 physisorption is dominant in both the system. Besides, the $\Delta H$ value is positive in both cases, 369 suggesting an endothermic nature of the process. As $\Delta \mathrm{H}>0$, i.e., higher temperature will favor 370 the elimination of MG and MB by MChi. Moreover, the higher value of $\Delta \mathrm{H}$ for MB than that of 
371 MG signifying that the interaction between $\mathrm{MB}$ and MChi was stronger and led to more

372 significant adsorption (Bayramoglu et al. 2009). The positive value of $\Delta S$ discloses the increase

373 in the degree of freedom at the solid-liquid interface during the fixation of adsorbate on the

374 adsorbing site of the MChi.

375

Table 4 Thermodynamic parameters for the MG and MB adsorption onto MChi (reaction

377 condition: $\mathrm{C}_{\mathrm{o}}=50 \mathrm{mg} \mathrm{L}{ }^{-1}$, MChi dose $=2 \mathrm{~g} \mathrm{~L}^{-1}, \mathrm{pH}=7, \mathrm{t}=210 \mathrm{~min}$ for $\mathrm{MG}$ and $\mathrm{C}_{\mathrm{o}}=50 \mathrm{mg} \mathrm{L}^{-1}$,

378 MChi dose $=1.2 \mathrm{~g} \mathrm{~L}^{-1}, \mathrm{pH}=7, \mathrm{t}=180 \min$ for $\mathrm{MB}$ )

\begin{tabular}{|c|c|c|c|c|c|c|c|c|}
\hline \multirow[b]{2}{*}{$\mathrm{T}(\mathrm{K})$} & \multicolumn{4}{|c|}{ MB } & \multicolumn{4}{|c|}{ MG } \\
\hline & 303 & 313 & 323 & 333 & 303 & 313 & 323 & 333 \\
\hline$-\Delta \mathrm{G}\left(\mathrm{kJ} \mathrm{mol}^{-1}\right)$ & 7.236 & 8.905 & 11.185 & 14.078 & 6.438 & 7.521 & 9.637 & 11.291 \\
\hline$\Delta \mathrm{H}\left(\mathrm{kJ} \mathrm{mol}^{-1}\right)$ & \multicolumn{4}{|c|}{61.683} & \multicolumn{4}{|c|}{44.065} \\
\hline$\Delta \mathrm{S}\left(\mathrm{J} \mathrm{K}^{-1} \mathrm{~mol}^{-1}\right)$ & \multicolumn{4}{|c|}{226.523} & \multicolumn{4}{|c|}{165.997} \\
\hline
\end{tabular}

379

Desorption and regeneration study

381 The economic viability of using adsorbent to eliminate pollutants from aqueous media depends 382 on its regeneration ability during repeated ad-/de-sorption cycles. In this research, various 383 desorbing agents $\left(\mathrm{C}_{2} \mathrm{H}_{5} \mathrm{OH}\right.$ and $\left.0.1 \mathrm{M} \mathrm{HCl}\right)$ were used in the batch system in order to determine a 384 suitable eluent for the desorption of cationic dyes (MG and MB) from the MChi. The findings 385 show that the maximum desorption for MG and MB was obtained with ethanol, and nearly 92.09 386 and $87.06 \%$ respectively, desorption was achieved under this condition as revealed in Fig. 10. 
387 The MChi was again subjected to adsorption experiments at the optimum conditions, and the ad388 /de-sorption cycles were repeated three times. The results (Fig. 10) showed that the desorption 389 percentage of MG and MB from the MChi was about 79.56 and $74.06 \%$ up to three cycles, with 390 the adsorption percentage of 67.57 and $73.31 \%$, respectively.

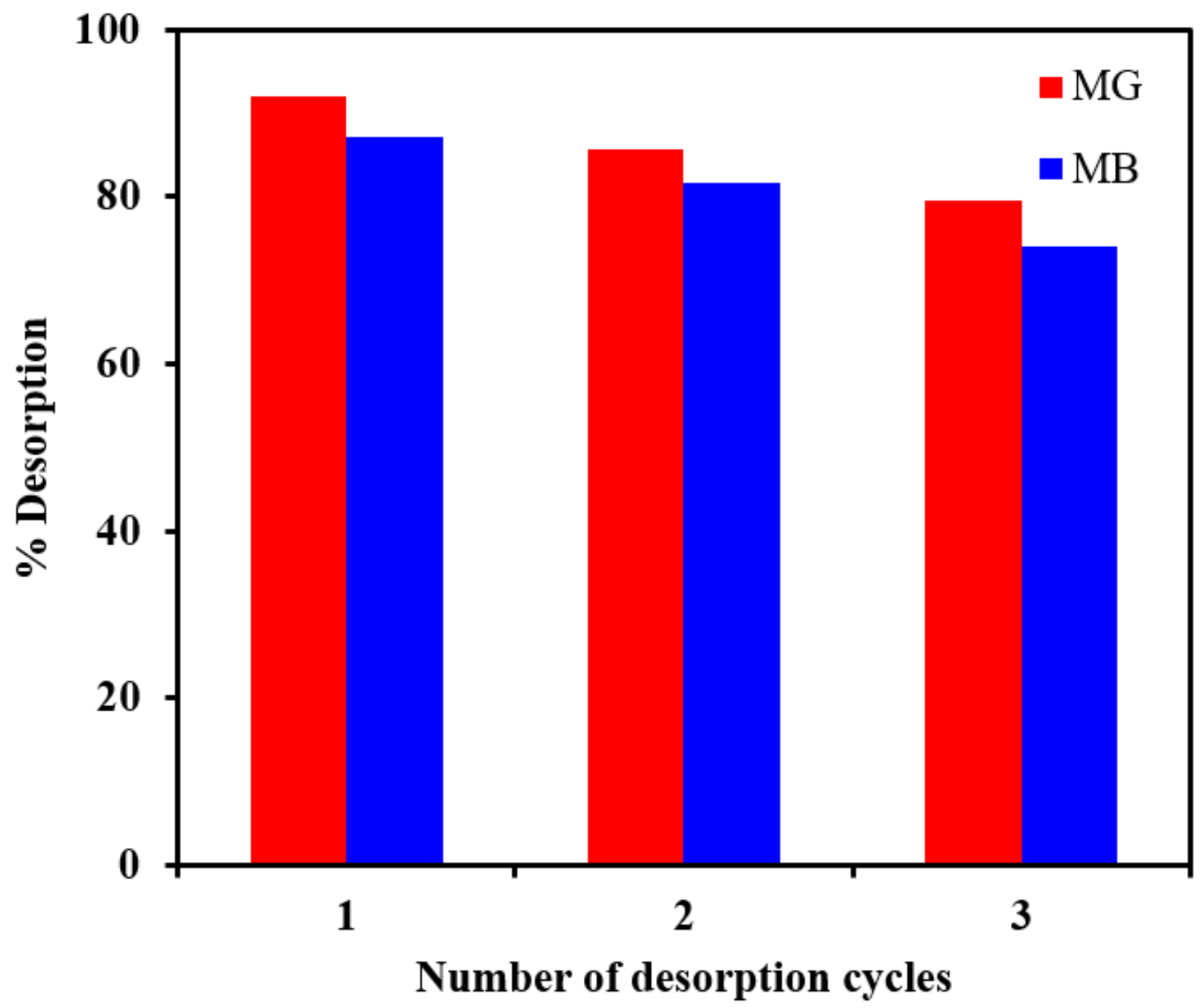

392 Fig. 10 Reusability of MChi after adsorption of MG and MB 


\section{Conclusion}

397 The present research emphasizes on the adsorption potential of magnetized chitosan (MChi) 398 towards the removal of cationic MG and MB dyes from aqueous media. The time-dependent 399 experimental data illustrated that 85.45 and $89.29 \%$ of the MG and MB could be eliminated 400 within 210 and $180 \mathrm{~min}$, respectively, which confirms its prospect for practical application. It 401 was perceived that MChi showed a greater adsorption efficiency for MB than MG. The higher 402 values of the correlation coefficient revealed that the adsorption process of dyes onto the MChi 403 followed Langmuir isotherms and pseudo-II ${ }^{\text {nd }}$-order kinetic models. The maximum monolayer 404 adsorption capacity for $\mathrm{MG}$ and $\mathrm{MB}$ dyes was obtained to be 55.87 and $76.34 \mathrm{mg}^{-1}$, 405 respectively at $303 \mathrm{~K}$. Thermodynamic analysis revealed that adsorption of both the dyes was 406 spontaneous and endothermic in nature. The desorption experiments unveiled that the MChi after 407 adsorption of MG and MB could be regenerated easily by ethanol. Overall, it can be concluded 408 that MChi fulfills the criteria of a probable adsorbent for $\mathrm{MG}$ and $\mathrm{MB}$ adsorption from 409 wastewater.

\section{Acknowledgments}

412 The authors thank the Chairperson of the Department of Applied Chemistry, Faculty of 413 Engineering and Technology, AMU, for extending laboratory facilities.

415 Data availability Not applicable

416 Ethics approval and consent to participate Not applicable 


\section{Conflict of interest}

418 The authors declare that they have no conflict of interests.

419 Funding information

420 Not applicable

421 Author Contributions Fouzia Mashkoor: Methodology, iinvestigation, interpation of

422 experimental data, formal anylysis, writing - original draft,

423 Abu Nasar: Conceptualisation, supervision, interpation of experimental data, writing -

424 review and editing, manuscript administration

425

426 Competing Interests

427 The authors declare no competing interests.

428

429

430

431

432

433

434

435

436

437

438

439

440

441 


\section{References}

447

448

449

450

451

452

453

454

455

456

457

458

459

460

461

462

463

464

465

466

467

468

469

470

471

472

473

474

475

476
Agarwal A, Verma AK, Yoshida M, et al (2020) A novel catalytic kinetic method for the determination of mercury (II) in water samples. RSC Adv 10:25100-25106. doi: 10.1039/D0RA03487H

Ahmed M, Mashkoor F, Nasar A (2020) Development, characterization, and utilization of magnetized orange peel waste as a novel adsorbent for the confiscation of crystal violet dye from aqueous solution. Groundw Sustain Dev 10:100322. doi: 10.1016/j.gsd.2019.100322

Arumugam TK, Krishnamoorthy P, Rajagopalan NR, et al (2019) Removal of malachite green from aqueous solutions using a modified chitosan composite. Int J Biol Macromol 128:655664. doi: 10.1016/j.ijbiomac.2019.01.185

Bagheri H, Roostaie A, Baktash MY (2014) A chitosan-polypyrrole magnetic nanocomposite as $\mu$-sorbent for isolation of naproxen. Anal Chim Acta 816:1-7. doi: 10.1016/j.aca.2014.01.028

Bayramoglu G, Altintas B, Arica MY (2009) Adsorption kinetics and thermodynamic parameters of cationic dyes from aqueous solutions by using a new strong cation-exchange resin. Chem Eng J 152:339-346. doi: 10.1016/j.cej.2009.04.051

Bekçi Z, Özveri C, Seki Y, Yurdakoç K (2008) Sorption of malachite green on chitosan bead. J Hazard Mater 154:254-261. doi: 10.1016/j.jhazmat.2007.10.021

Cabuk M, Alan Y, Yavuz M, Unal HI (2014) Synthesis, characterization and antimicrobial activity of biodegradable conducting polypyrrole-graft-chitosan copolymer. Appl Surf Sci 318:168-175. doi: 10.1016/j.apsusc.2014.02.180

Cao C, Xiao L, Chen C, et al (2014) In situ preparation of magnetic $\mathrm{Fe}_{3} \mathrm{O}_{4}$ /chitosan nanoparticles via a novel reduction-precipitation method and their application in adsorption of reactive azo dye. Powder Technol 260:90-97. doi: 10.1016/j.powtec.2014.03.025

Chen B, Zhao H, Chen S, et al (2019) A magnetically recyclable chitosan composite adsorbent functionalized with EDTA for simultaneous capture of anionic dye and heavy metals in complex wastewater. Chem Eng J 356:69-80. doi: 10.1016/j.cej.2018.08.222

Cho D-W, Jeon B-H, Chon C-M, et al (2015) Magnetic chitosan composite for adsorption of cationic and anionic dyes in aqueous solution. J Ind Eng Chem 28:60-66. doi: 10.1016/j.jiec.2015.01.023 
Debrassi A, Corrêa AF, Baccarin T, et al (2012) Removal of cationic dyes from aqueous solutions using N-benzyl-O-carboxymethylchitosan magnetic nanoparticles. Chem Eng J 183:284-293. doi: 10.1016/j.cej.2011.12.078

Du Q, Sun J, Li Y, et al (2014) Highly enhanced adsorption of congo red onto graphene oxide/chitosan fibers by wet-chemical etching off silica nanoparticles. Chem Eng J 245:99106. doi: $10.1016 /$ j.cej.2014.02.006

Fan L, Luo C, Li X, et al (2012) Fabrication of novel magnetic chitosan grafted with graphene oxide to enhance adsorption properties for methyl blue. J Hazard Mater 215-216:272-279. doi: 10.1016/j.jhazmat.2012.02.068

Foo KY, Hameed BH (2010) Insights into the modeling of adsorption isotherm systems. Chem Eng J 156:2-10. doi: 10.1016/j.cej.2009.09.013

Franco EG, Kastner A, Kuritzky M, Lukacs R (2019) Regional risks for doing business 2019. World Econ Forum 1-40.

Hasan I, Bhatia D, Walia S, Singh P (2020) Removal of malachite green by polyacrylamide-gchitosan $\gamma-\mathrm{Fe}_{2} \mathrm{O}_{3}$ nanocomposite-an application of central composite design. Groundw Sustain Dev 11:100378. doi: 10.1016/j.gsd.2020.100378

Hokkanen S, Bhatnagar A, Sillanpää M (2016) A review on modification methods to cellulosebased adsorbents to improve adsorption capacity. Water Res 91:156-173. doi: 10.1016/j.watres.2016.01.008

Ippolito A, Fait G (2019) Pesticides in surface waters: from edge-of-field to global modelling. Curr Opin Environ Sustain 36:78-84. doi: 10.1016/j.cosust.2018.10.023

Jafari S, Zhao F, Zhao D, et al (2015) A comparative study for the removal of methylene blue dye by $\mathrm{N}$ and $\mathrm{S}$ modified $\mathrm{TiO}_{2}$ adsorbents. J Mol Liq 207:90-98. doi: 10.1016/j.molliq.2015.03.026

Jain SN, Shaikh Z, Mane VS, et al (2019) Nonlinear regression approach for acid dye remediation using activated adsorbent: Kinetic, isotherm, thermodynamic and reusability studies. Microchem J 148:605-615. doi: 10.1016/j.microc.2019.05.024

Jain SN, Tamboli SR, Sutar DS, et al (2020) Batch and continuous studies for adsorption of anionic dye onto waste tea residue: Kinetic, equilibrium, breakthrough and reusability studies. J Clean Prod 252:119778. doi: 10.1016/j.jclepro.2019.119778

Kang S, Qin L, Zhao Y, et al (2020) Enhanced removal of methyl orange on exfoliated montmorillonite/chitosan gel in presence of methylene blue. Chemosphere 238:124693. doi: 10.1016/j.chemosphere.2019.124693

Kant R (2012) Textile dyeing industry an environmental hazard. Nat Sci 4:22-26. doi: 10.4236/ns.2012.41004

Kazeminezhad I, Mosivand S (2014) Phase Transition of Electrooxidized $\mathrm{Fe}_{3} \mathrm{O}_{4}$ to $\gamma$ and $\alpha-\mathrm{Fe}_{2} \mathrm{O}_{3}$ Nanoparticles Using Sintering Treatment. Acta Phys Pol A 125:1210-1214. doi: 
515

Kuo C-Y, Wu C-H, Wu J-Y (2008) Adsorption of direct dyes from aqueous solutions by carbon nanotubes: Determination of equilibrium, kinetics and thermodynamics parameters. $\mathrm{J}$ Colloid Interface Sci 327:308-315. doi: 10.1016/j.jcis.2008.08.038

Lehman JH, Terrones M, Mansfield E, et al (2011) Evaluating the characteristics of multiwall carbon nanotubes. Carbon N Y 49:2581-2602. doi: 10.1016/j.carbon.2011.03.028

Li X, Li J, Sun X, et al (2015) Preparation and malachite green adsorption behavior of polyurethane/chitosan composite foam. J Cell Plast 51:373-386. doi: $10.1177 / 0021955 X 14542538$

Lou T, Yan X, Wang X (2019) Chitosan coated polyacrylonitrile nanofibrous mat for dye adsorption. Int J Biol Macromol 135:919-925. doi: 10.1016/j.ijbiomac.2019.06.008

Mane VS, Vijay Babu PV (2013) Kinetic and equilibrium studies on the removal of Congo red from aqueous solution using Eucalyptus wood (Eucalyptus globulus) saw dust. J Taiwan Inst Chem Eng 44:81-88. doi: 10.1016/j.jtice.2012.09.013

Marrakchi F, Khanday WA, Asif M, Hameed BH (2016) Cross-linked chitosan/sepiolite composite for the adsorption of methylene blue and reactive orange 16. Int J Biol Macromol 93:1231-1239. doi: 10.1016/j.ijbiomac.2016.09.069

Mashkoor F, Nasar A (2020a) Magsorbents: Potential candidates in wastewater treatment technology - A review on the removal of methylene blue dye. J. Magn. Magn. Mater. 500:166408.

Mashkoor F, Nasar A (2020b) Facile synthesis of polypyrrole decorated chitosan-based magsorbent: Characterizations, performance, and applications in removing cationic and anionic dyes from aqueous medium. Int J Biol Macromol 161:88-100. doi: 10.1016/j.ijbiomac.2020.06.015

Mashkoor F, Nasar A (2019a) Preparation, characterization and adsorption studies of the chemically modified Luffa aegyptica peel as a potential adsorbent for the removal of malachite green from aqueous solution. J Mol Liq 274:315-327. doi: 10.1016/j.molliq.2018.10.119

Mashkoor F, Nasar A (2020c) Magnetized Tectona grandis sawdust as a novel adsorbent: preparation, characterization, and utilization for the removal of methylene blue from aqueous solution. Cellulose. doi: 10.1007/s10570-019-02918-8

Mashkoor F, Nasar A (2019b) Polyaniline/Tectona grandis sawdust: A novel composite for efficient decontamination of synthetically polluted water containing crystal violet dye. Groundw Sustain Dev 8:390-401. doi: 10.1016/j.gsd.2018.12.008

Mashkoor F, Nasar A, Inamuddin (2020) Carbon nanotube-based adsorbents for the removal of dyes from waters: A review. Environ Chem Lett. doi: 10.1007/s10311-020-00970-6

Mashkoor F, Nasar A, Inamuddin, Asiri AM (2018) Exploring the reusability of synthetically 

contaminated wastewater containing crystal violet dye using Tectona grandis sawdust as a very low-cost adsorbent. Sci Rep 8:8314. doi: 10.1038/s41598-018-26655-3

Mokhtar A, Abdelkrim S, Djelad A, et al (2020) Adsorption behavior of cationic and anionic dyes on magadiite-chitosan composite beads. Carbohydr Polym 229:115399. doi: 10.1016/j.carbpol.2019.115399

Nasar A, Mashkoor F (2019) Application of polyaniline-based adsorbents for dye removal from water and wastewater-a review. Environ Sci Pollut Res 26:5333-5356. doi: 10.1007/s11356-018-3990-y

Naseeruteen F, Hamid NSA, Suah FBM, et al (2018) Adsorption of malachite green from aqueous solution by using novel chitosan ionic liquid beads. Int J Biol Macromol 107:12701277. doi: 10.1016/j.ijbiomac.2017.09.111

Novais RM, Ascensão G, Tobaldi DM, et al (2018) Biomass fly ash geopolymer monoliths for effective methylene blue removal from wastewaters. J Clean Prod 171:783-794. doi: 10.1016/j.jclepro.2017.10.078

Prasad AR, Joseph A (2017) Synthesis, characterization and investigation of methyl orange dye removal from aqueous solutions using waterborne poly vinyl pyrrolidone (PVP) stabilized poly aniline (PANI) core-shell nanoparticles. RSC Adv 7:20960-20968. doi: 10.1039/C7RA01790A

Qamruzzaman, Nasar A (2015) Degradation of acephate by colloidal manganese dioxide in the absence and presence of surfactants. Desalin Water Treat 55:2155-2164. doi: $10.1080 / 19443994.2014 .937752$

Qamruzzaman, Nasar A (2019) Degradative treatment of bispyribac sodium herbicide from synthetically contaminated water by colloidal $\mathrm{MnO}_{2}$ dioxide in the absence and presence of surfactants. Environ Technol 40:451-457. doi: 10.1080/09593330.2017.1396500

Qi L, Tang X, Wang Z, Peng X (2017) Pore characterization of different types of coal from coal and gas outburst disaster sites using low temperature nitrogen adsorption approach. Int $\mathbf{J}$ Min Sci Technol 27:371-377. doi: 10.1016/j.ijmst.2017.01.005

Quesada HB, Baptista ATA, Cusioli LF, et al (2019) Surface water pollution by pharmaceuticals and an alternative of removal by low-cost adsorbents: A review. Chemosphere 222:766780. doi: 10.1016/j.chemosphere.2019.02.009

Rahmi, Ishmaturrahmi, Mustafa I (2019) Methylene blue removal from water using $\mathrm{H}_{2} \mathrm{SO}_{4}$ crosslinked magnetic chitosan nanocomposite beads. Microchem J 144:397-402. doi: 10.1016/j.microc.2018.09.032

Sabar S, Aziz HA, Yusof NH, et al (2020) Preparation of sulfonated chitosan for enhanced adsorption of methylene blue from aqueous solution. React Funct Polym 104584. doi: 10.1016/j.reactfunctpolym.2020.104584

Saravanakumar R, Muthukumaran K, Selvaraju N (2019) Enhanced Pb (II) ions removal by using magnetic NiO/Biochar composite. Mater Res Express 6:105504. doi: 10.1088/2053- 
602

603

604

605

606

607

608

609

610

611

612

613

614

615

616

617

618

619

620

621

622

623

624

625

Sewu DD, Jung H, Kim SS, et al (2019) Decolorization of cationic and anionic dye-laden wastewater by steam-activated biochar produced at an industrial-scale from spent mushroom substrate. Bioresour Technol 277:77-86. doi: 10.1016/j.biortech.2019.01.034

Shakoor S, Nasar A (2016) Removal of methylene blue dye from artificially contaminated water using citrus limetta peel waste as a very low cost adsorbent. J Taiwan Inst Chem Eng 66:154-163. doi: 10.1016/j.jtice.2016.06.009

Shakoor S, Nasar A (2017) Adsorptive treatment of hazardous methylene blue dye from artificially contaminated water using cucumis sativus peel waste as a low-cost adsorbent. Groundw Sustain Dev 5:152-159. doi: 10.1016/j.gsd.2017.06.005

Tan KL, Hameed BH (2017) Insight into the adsorption kinetics models for the removal of contaminants from aqueous solutions. J Taiwan Inst Chem Eng 74:25-48. doi: 10.1016/j.jtice.2017.01.024

Tehrani-Bagha AR, Nikkar H, Mahmoodi NM, et al (2011) The sorption of cationic dyes onto kaolin: Kinetic, isotherm and thermodynamic studies. Desalination 266:274-280. doi: 10.1016/j.desal.2010.08.036

Tomar V, Prasad S, Kumar D (2014) Adsorptive removal of fluoride from aqueous media using Citrus limonum (lemon) leaf. Microchem J 112:97-103. doi: 10.1016/j.microc.2013.09.010

Vakili M, Deng S, Cagnetta G, et al (2019) Regeneration of chitosan-based adsorbents used in heavy metal adsorption: A review. Sep Purif Technol 224:373-387. doi: 10.1016/j.seppur.2019.05.040

Wang P, Ma Q, Hu D, Wang L (2015) Removal of Reactive Blue 21 onto magnetic chitosan microparticles functionalized with polyamidoamine dendrimers. React Funct Polym 9192:43-50. doi: 10.1016/j.reactfunctpolym.2015.04.007

Yan H, Li H, Yang H, et al (2013) Removal of various cationic dyes from aqueous solutions using a kind of fully biodegradable magnetic composite microsphere. Chem Eng J 223:402411. doi: 10.1016/j.cej.2013.02.113

Zayed AM, Abdel Wahed MSM, Mohamed EA, Sillanpää M (2018) Insights on the role of organic matters of some Egyptian clays in methyl orange adsorption: Isotherm and kinetic studies. Appl Clay Sci 166:49-60. doi: 10.1016/j.clay.2018.09.013

Zeng L, Xie M, Zhang Q, et al (2015) Chitosan/organic rectorite composite for the magnetic uptake of methylene blue and methyl orange. Carbohydr Polym 123:89-98. doi: 10.1016/j.carbpol.2015.01.021

Zhao F, Repo E, Yin D, et al (2015) EDTA-cross-linked $\beta$-cyclodextrin: An environmentally friendly bifunctional adsorbent for simultaneous adsorption of metals and cationic dyes. Environ Sci Technol 49:10570-10580. doi: 10.1021/acs.est.5b02227

Zhao F, Repo E, Yin D, Sillanpää MET (2013) Adsorption of Cd(II) and Pb(II) by a novel 
631

632

633

634

635

636

637

638

639

640

641

642

643

644

\section{1}

40

EGTA-modified chitosan material: Kinetics and isotherms. J Colloid Interface Sci 409:174182. doi: 10.1016/j.jcis.2013.07.062

Zhu Y, Xue J, Xu T, et al (2017) Enhanced photocatalytic activity of magnetic core-shell $\mathrm{Fe}_{3} \mathrm{O}_{4} @ \mathrm{Bi}_{2} \mathrm{O}_{3}-\mathrm{RGO}$ heterojunctions for quinolone antibiotics degradation under visible light. J Mater Sci Mater Electron 28:8519-8528. doi: 10.1007/s10854-017-6574-6

2

3

634

5

36

637

38


Figures

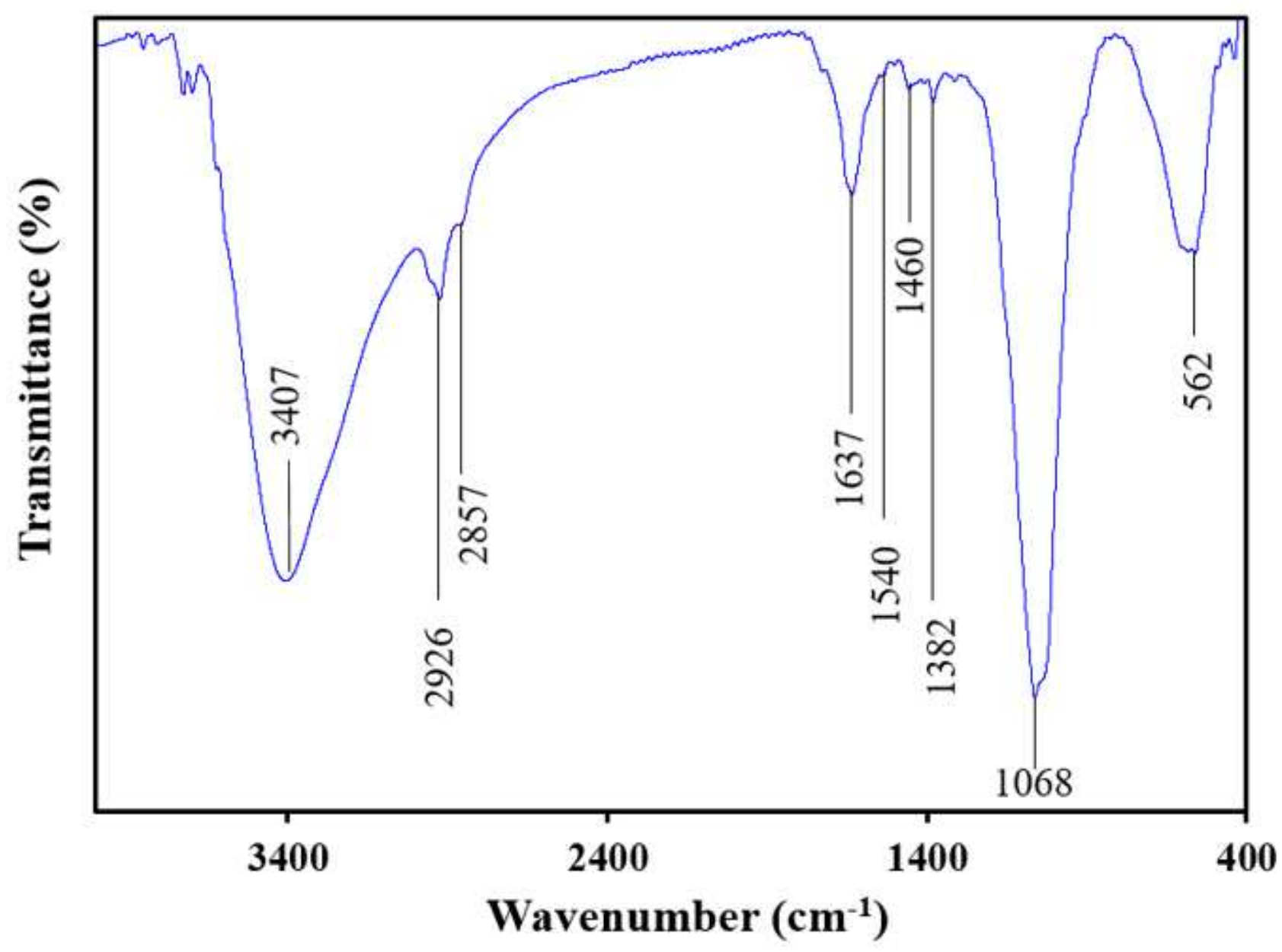

Figure 1

(a) FTIR of MChi 

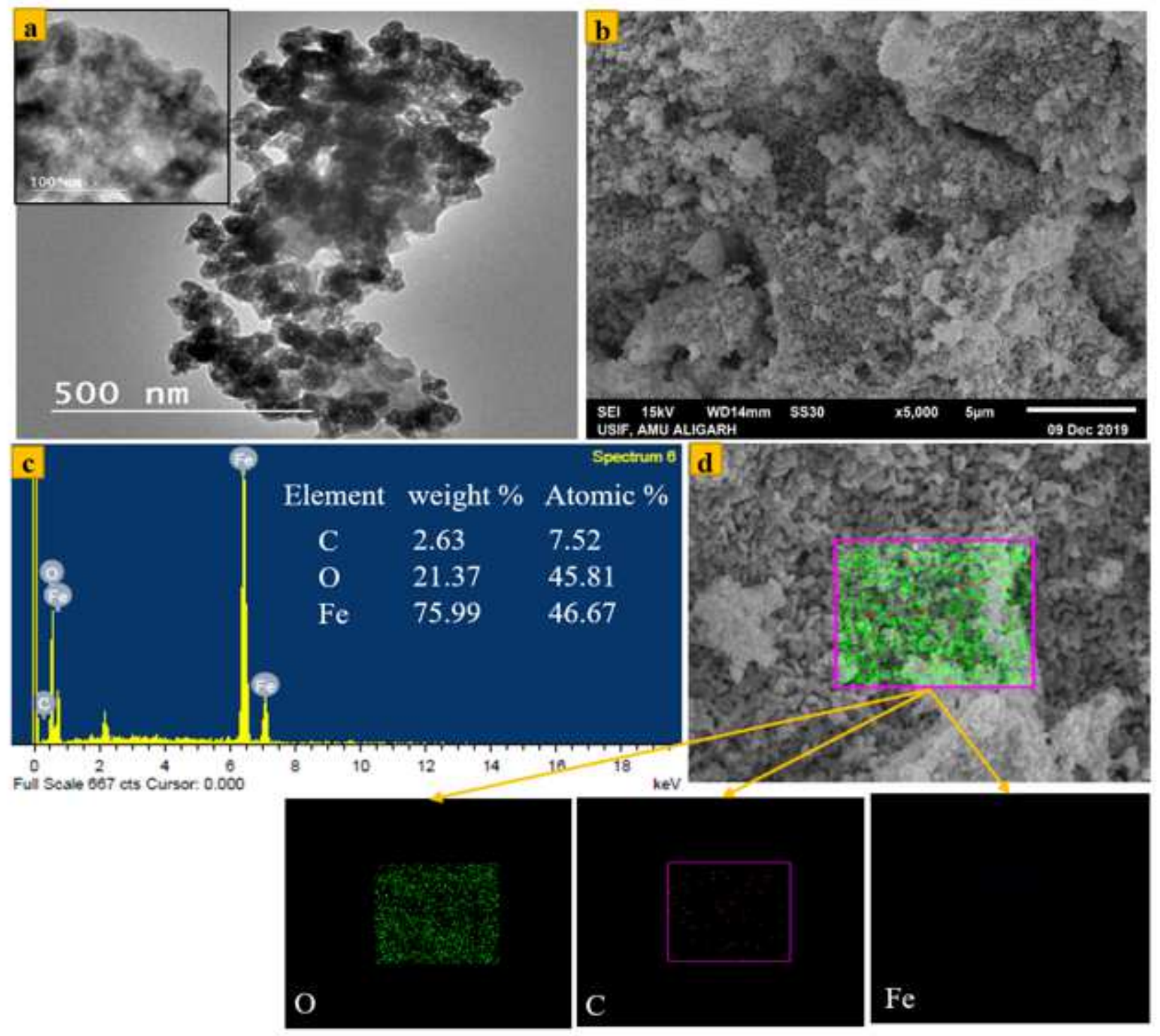

Figure 2

(a) TEM images (b) SEM image (c) EDAX image (d) Elemental mapping of MChi 


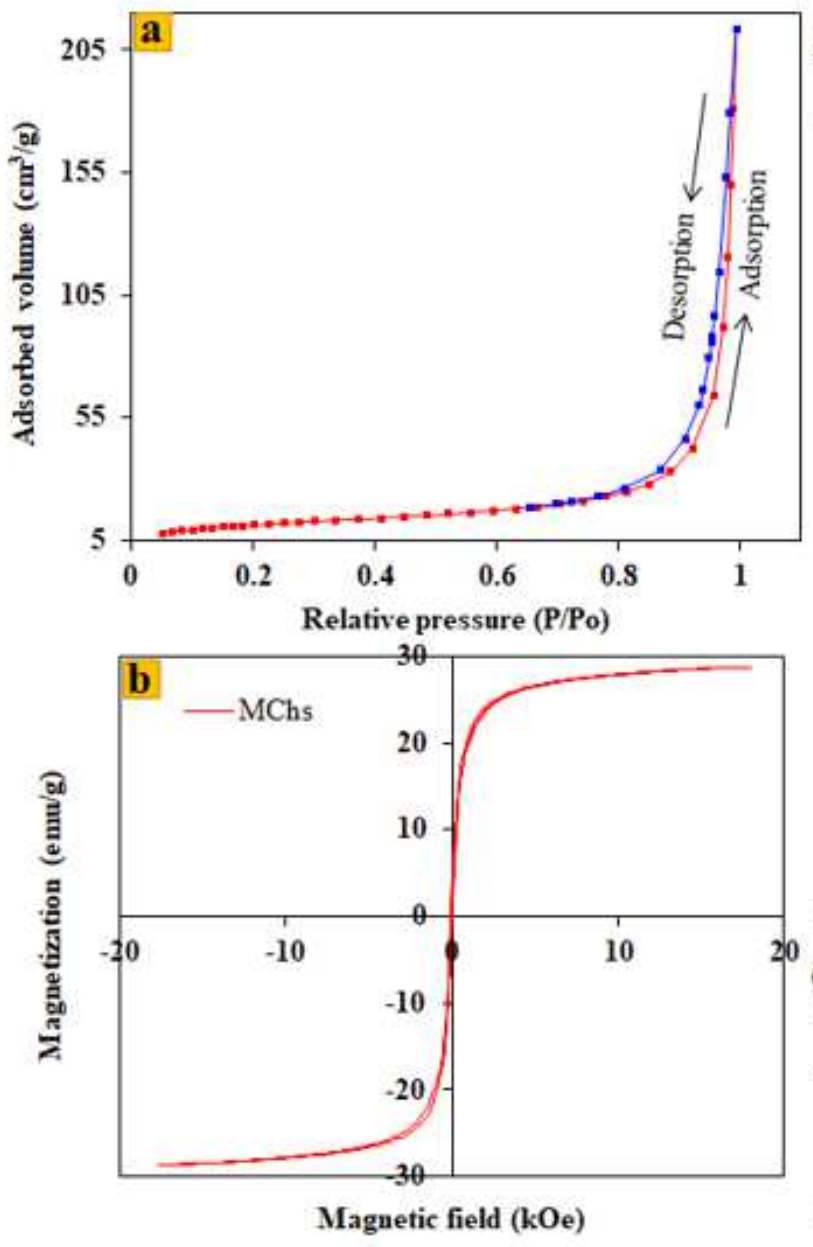

(a') Summary of the BET analysis of MChi

Parameters Values

Single-point surface area at $\mathrm{P} / \mathrm{P}_{\mathrm{o}}=0.3001 \quad 38.4813 \mathrm{~m}^{2} / \mathrm{g}$

Single-point adsorption total pore volume of $0.33003 \mathrm{~cm}^{3} / \mathrm{g}$

the pores (pores less than 2988.714 $\AA$

diameter at $\mathrm{P} / \mathrm{P}_{0}=0.993559$ )

BET surface area $\quad 39.9930 \mathrm{~m}^{2} / \mathrm{g}$

Adsorption average pore width (4V/A by $33.00897 \mathrm{~nm}$ BET)

t-plot external surface area $\quad 39.1537 \mathrm{~m}^{2} / \mathrm{g}$

t-plot micropore area $\quad 0.8393 \mathrm{~m}^{2} / \mathrm{g}$

t-plot micropore volume $\quad 0.000187 \mathrm{~cm}^{3} / \mathrm{g}$

$\mathrm{BJH}$ adsorption cumulative surface area of $33.553 \mathrm{~m}^{2} / \mathrm{g}$ pores between 17-3000 $\AA$ diameter

$\mathrm{BJH}$ adsorption average pore width (4V/A by $38.9751 \mathrm{~nm}$ BET)

BJH desorption cumulative surface area of $36.7427 \mathrm{~m}^{2} / \mathrm{g}$ pores between 17-3000 $\AA$ diameter

$\mathrm{BJH}$ desorption average pore width (4V/A by $35.8733 \mathrm{~nm}$ BET)

(b') Magnetic properties of MChi

\begin{tabular}{ll}
\hline Parameters & Values \\
\hline Coercivity $(\mathrm{Hc})$ & $54.507 \mathrm{Oe}$ \\
Magnetization $(\mathrm{Ms})$ & $28.645 \mathrm{emu} / \mathrm{g}$ \\
Retentivity $(\mathrm{M})$ & $2.9258 \mathrm{emu} / \mathrm{g}$ \\
\hline
\end{tabular}

\section{Figure 3}

(a) N2 ad-/de-sorption isotherm, (a') Summary of the BET analyses (b) Magnetization curve (b') Magnetic properties of MChi 

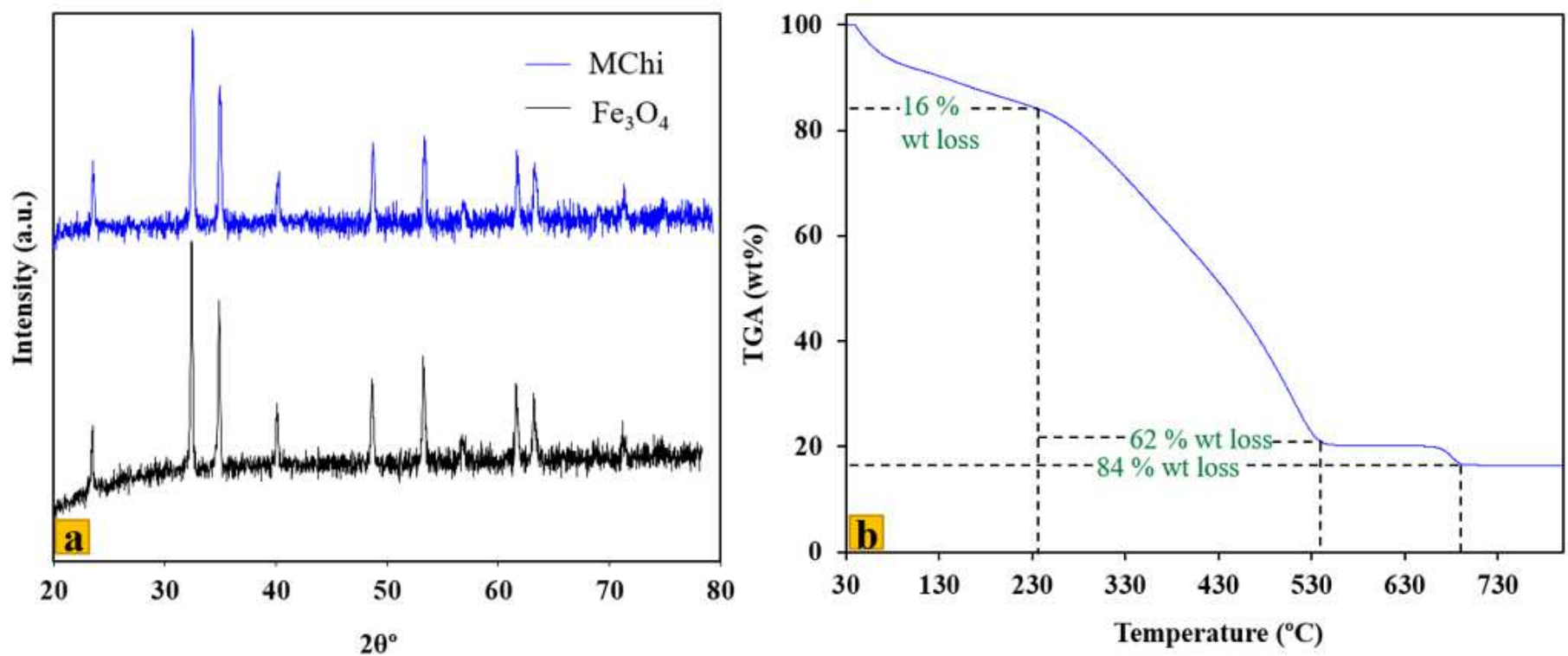

Figure 4

XRD patterns of Fe304, and MChi (b)TGA plot of MChi 


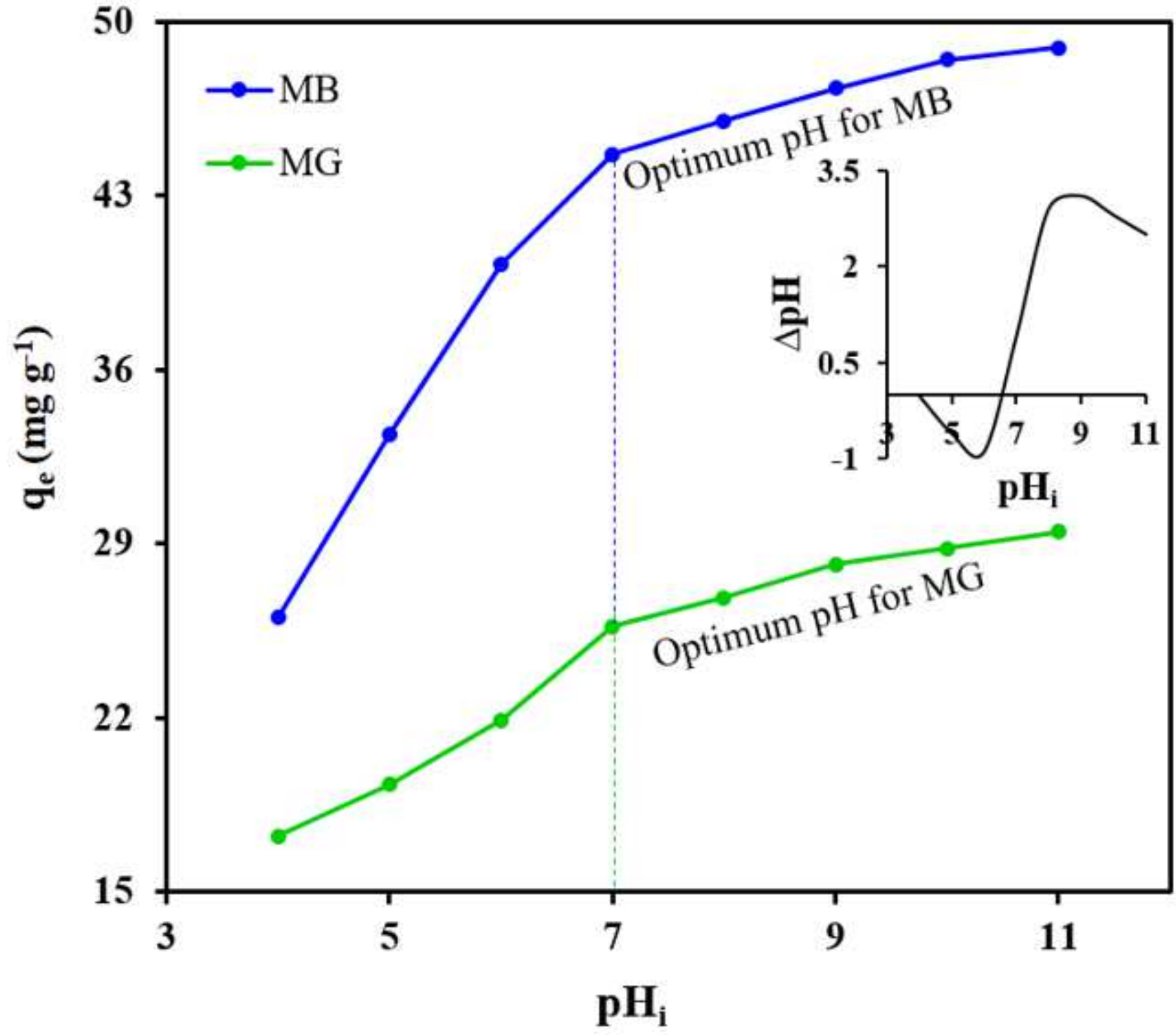

Figure 5

Effect of pH on adsorption capacity of MChs (inset-point of zero charge of MChi) 


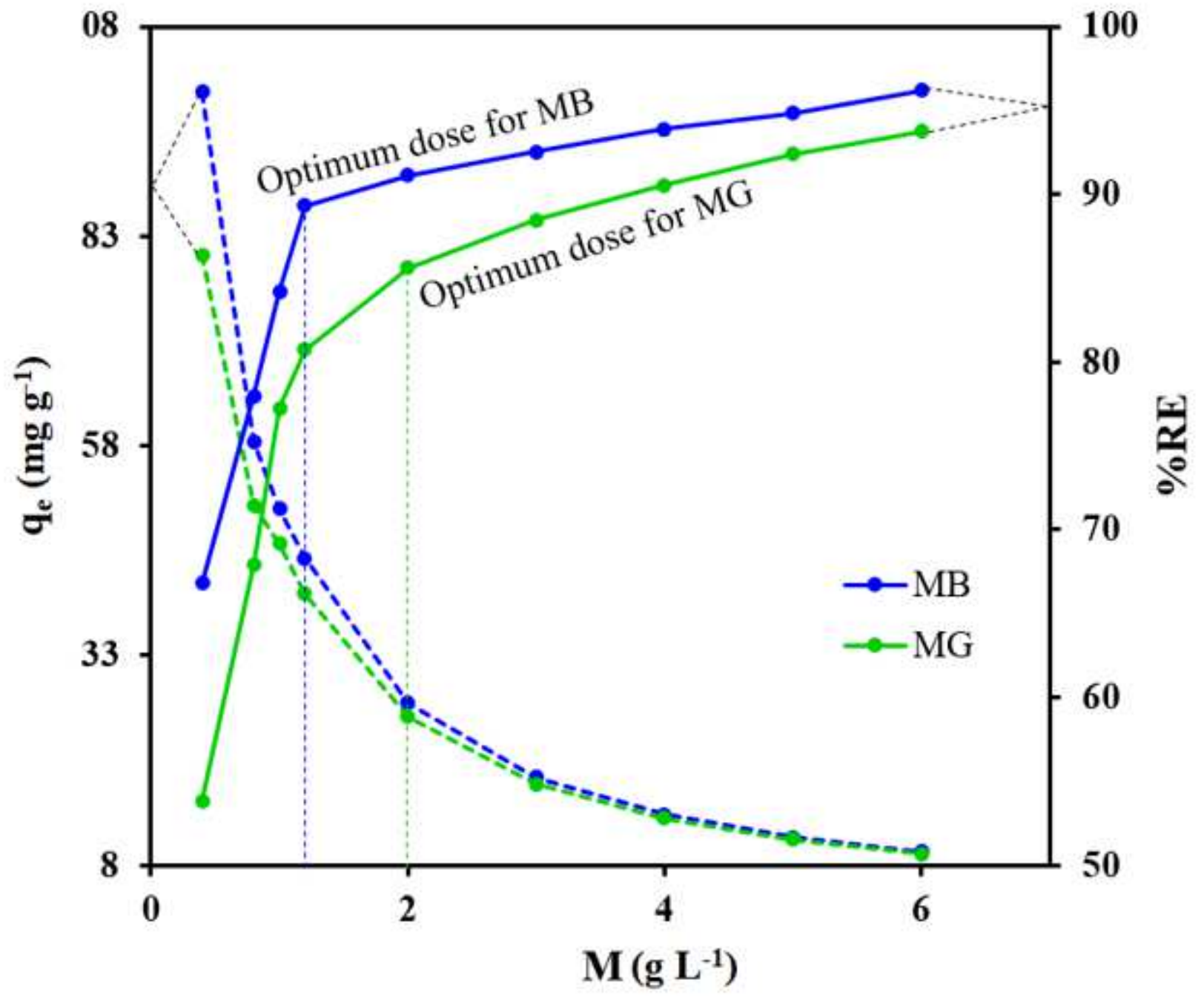

Figure 6

Effect of MChs dose on adsorption capacity (qe) and removal efficiency (\% RE) of MChi 


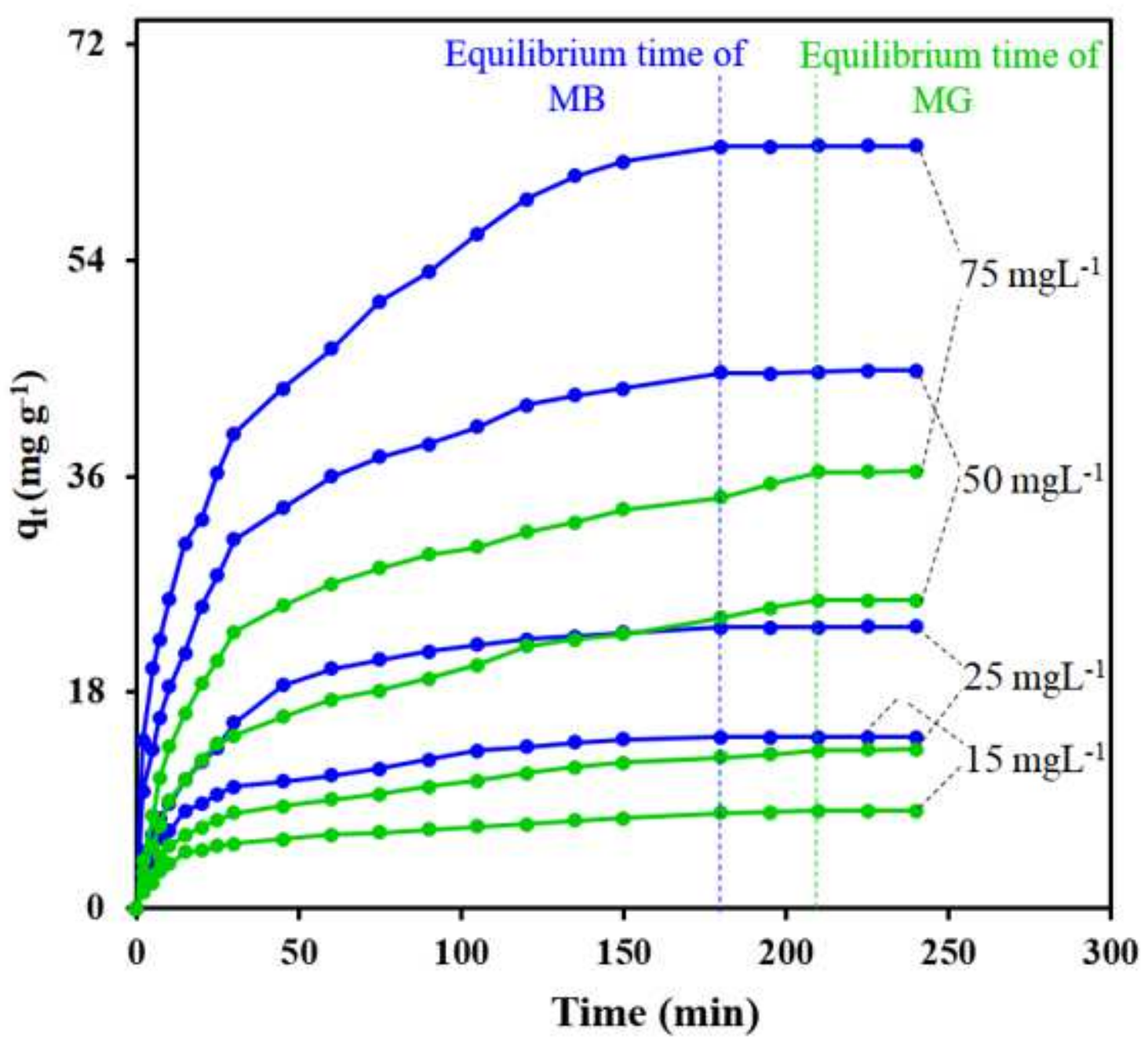

Figure 7

Effect of contact time on adsorption capacity of MChi 


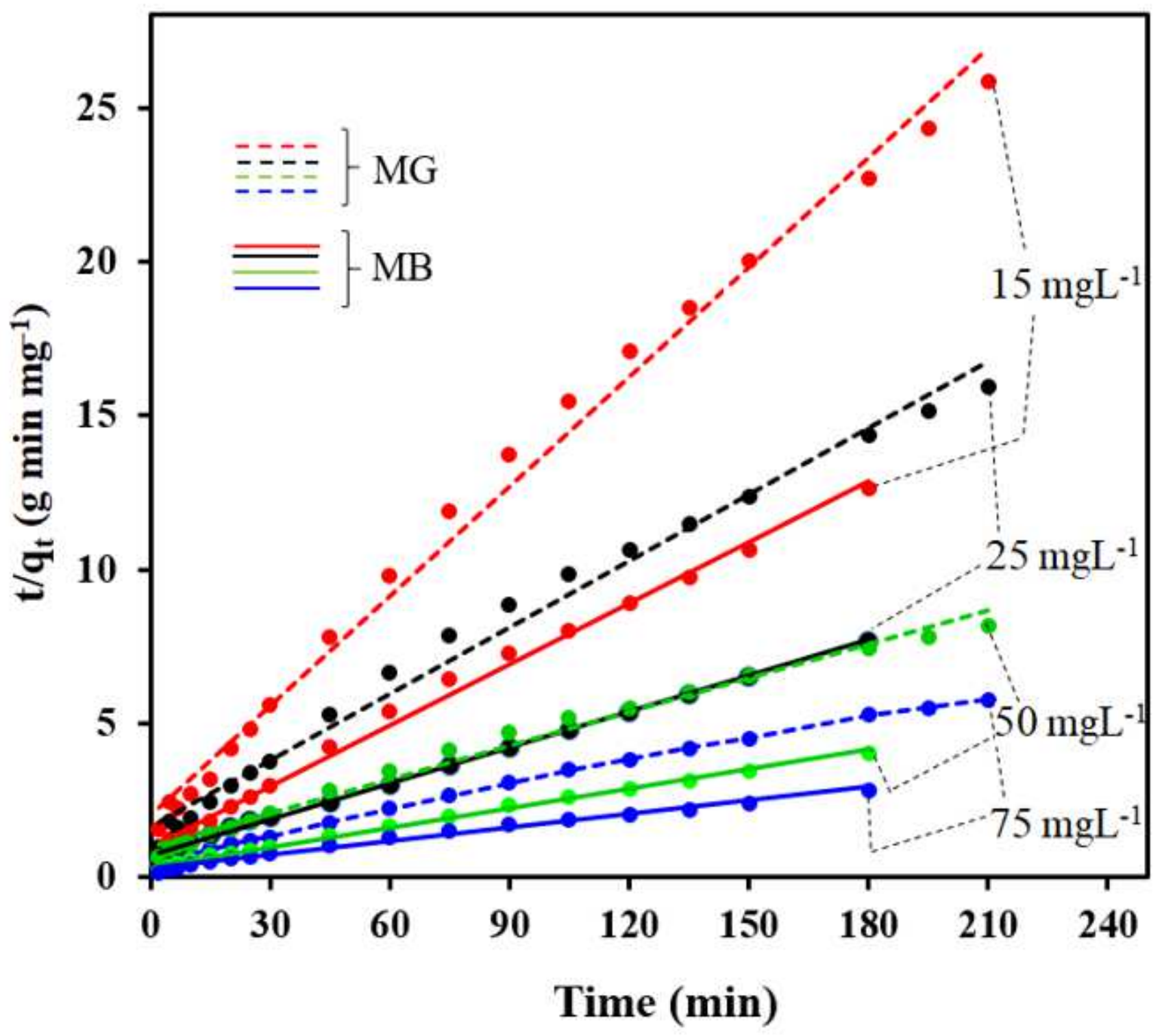

Figure 8

Pseudo-IInd-order plot for the MG and MB adsorption onto the MChi 


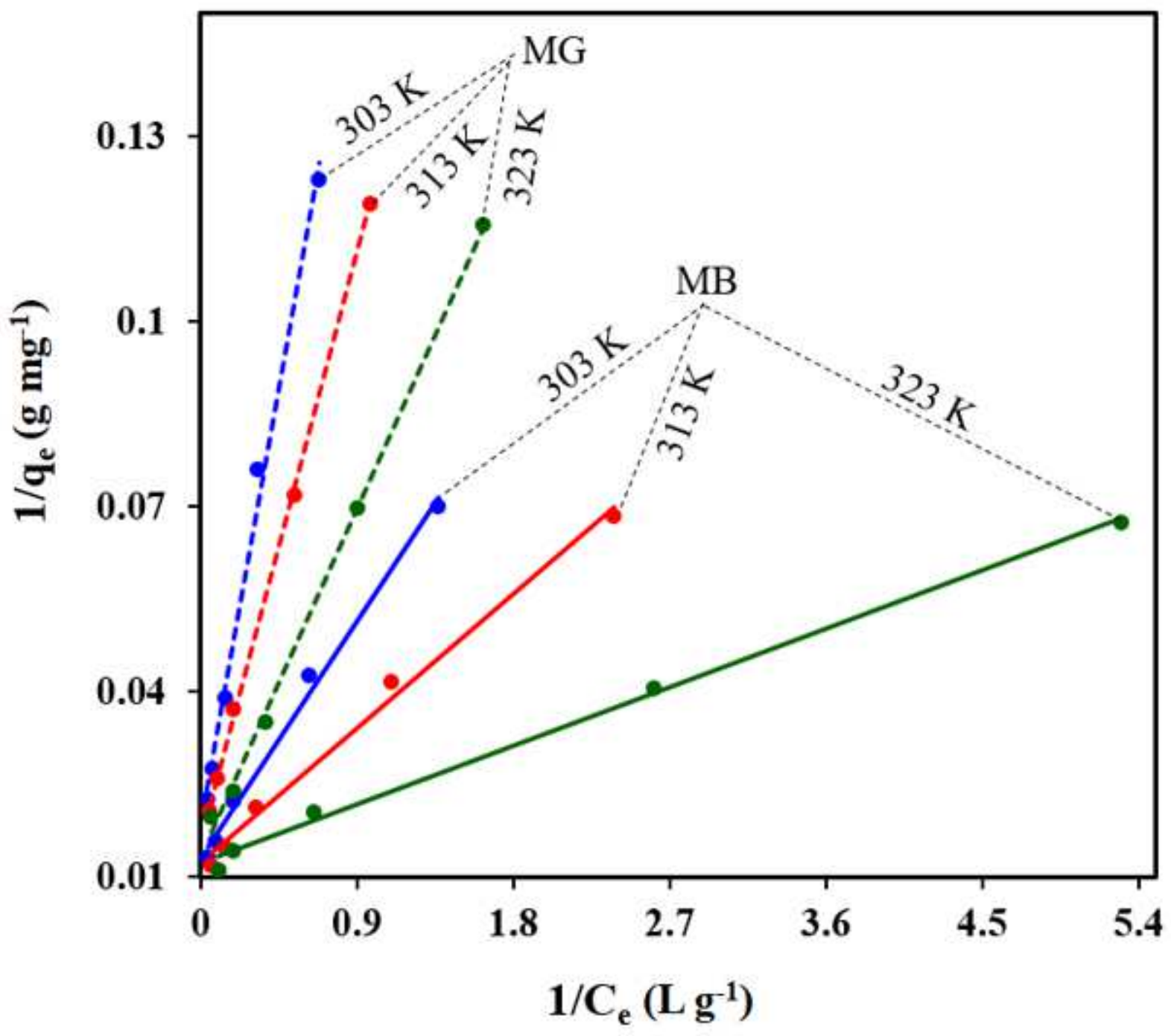

Figure 9

Langmuir model for the MG and MB adsorption onto the MChi 


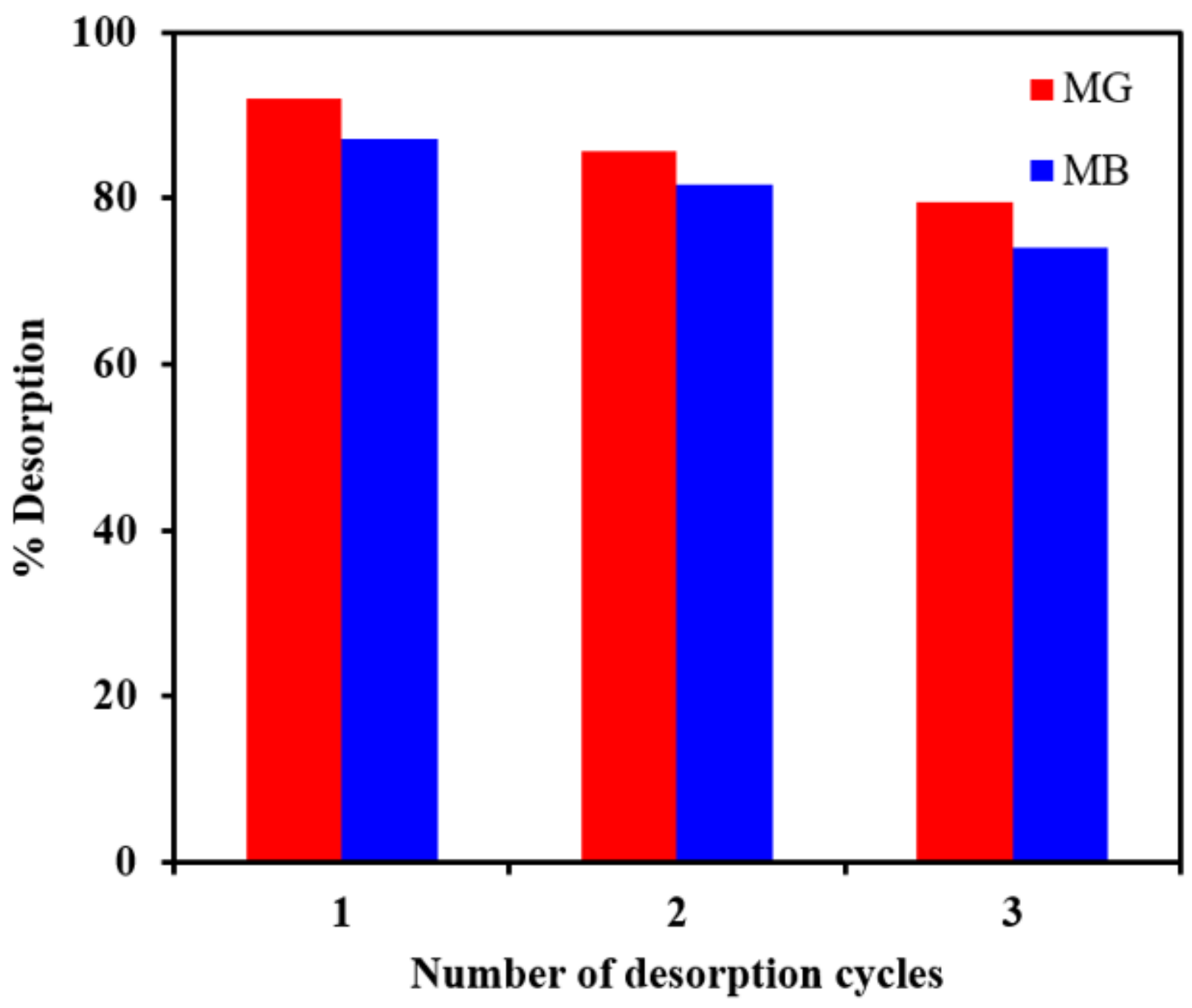

Figure 10

Reusability of MChi after adsorption of MG and MB

\section{Supplementary Files}

This is a list of supplementary files associated with this preprint. Click to download.

- TextS1.docx 